\title{
Simulation of Ground Motion Using the Stochastic Method
}

\author{
DAVID M. BOORE ${ }^{1}$
}

\begin{abstract}
A simple and powerful method for simulating ground motions is to combine parametric or functional descriptions of the ground motion's amplitude spectrum with a random phase spectrum modified such that the motion is distributed over a duration related to the earthquake magnitude and to the distance from the source. This method of simulating ground motions often goes by the name "the stochastic method." It is particularly useful for simulating the higher-frequency ground motions of most interest to engineers (generally, $f>0.1 \mathrm{~Hz}$ ), and it is widely used to predict ground motions for regions of the world in which recordings of motion from potentially damaging earthquakes are not available. This simple method has been successful in matching a variety of ground-motion measures for earthquakes with seismic moments spanning more than 12 orders of magnitude and in diverse tectonic environments. One of the essential characteristics of the method is that it distills what is known about the various factors affecting ground motions (source, path, and site) into simple functional forms. This provides a means by which the results of the rigorous studies reported in other papers in this volume can be incorporated into practical predictions of ground motion.
\end{abstract}

Key words: Stochastic, simulation, ground motion, random vibration, earthquake, strong motion, site amplification.

\section{Introduction}

Keiiti Aki was one of the first seismologists to derive an expression for the spectrum of seismic waves radiated from complex faulting. In a 1967 paper (AKI, 1967) he used assumptions about the form of the autocorrelation function of slip as a function of space and time to derive an $\omega$-square model of the spectrum (and he coined the term " $\omega$-square model" in that paper). He then used the assumption of similarity to derive a source-scaling law, showing that the spectral amplitude at the corner frequency goes as the inverse-cube power of the corner frequency. He explicitly recognized that this is a constant-stress-drop model. His work has been used knowingly and unknowingly by several generations of seismologists to predict ground motions for earthquakes, particularly at high frequencies where the spaceand time-distribution of fault slip is complicated enough to warrant a stochastic description of the source. Usually these predictions are for a specified seismic

${ }^{1}$ U.S. Geological Survey, Mail Stop 977, 345 Middlefield Road, Menlo Park, California 94025, U.S.A. E-mail: boore@usgs.gov 
moment, and this is another place in which Kei's work had a long-term impact: in 1966 (AKI, 1966) he determined the seismic moment of an earthquake for the first time and also explicitly related the seismic moment to the product of rigidity, slip, and fault area. His research on the shape and scaling of source spectra and on seismic moment form the basis for the method for simulating ground motions discussed in this paper. In recognition of its use of a partially stochastic, rather than a completely deterministic, description of the source and path, this method is often referred to as "the stochastic model" or "the stochastic method." A word about terminology may be in order here: I refer to the means of simulating ground motions as the "stochastic method," whereas a particular application of the method results in a "stochastic model" of the ground motion (often associated with a particular study, such as the FRANKEL et al. (1996) model). The terminology is not standardized, however, and more usually (and loosely) people refer to any application of the stochastic method as the stochastic model; the distinction between the two is important, because the ground motions for different applications of the method (different models) might be very different.

There are several methods that use stochastic representations of some or all of the physical processes responsible for ground shaking (e.g., PAPAGEORGIOU and AKI, 1983a; ZENG et al., 1994). In this paper I review the particular stochastic method that I and a number of others developed in the last several decades. The paper includes a few new figures and an improvement in the calculation of random vibration results that previously appeared only in an USGS open-file report (BoORE, 1996), Other authors have published papers applying the stochastic method and extending the method in various ways. Table 1 contains a partial list of papers primarily concerned with development of the method; a table of references applying the method is given later.

Most of the discussion assumes that the motions to be simulated are $S$ wavesthese are the most important motions for seismic hazard. The method can be modified to simulate $P$-wave motions, as was done in Boore (1986).

\section{The Essence of the Method}

The stochastic method described in this paper has its basis in the work of Hanks and McGuire, who combined seismological models of the spectral amplitude of ground motion with the engineering notion that high-frequency motions are basically random (HANKs, 1979; MCGuire and Hanks, 1980; HANKS and MCGuire, 1981). Assuming that the far-field accelerations on an elastic half space are band-limited, finite-duration, white Gaussian noise, and that the source spectra are described by a single corner-frequency model whose corner frequency depends on earthquake size according to the BRUNE $(1970,1971)$ scaling, they derived a remarkably simple relationship for peak acceleration that was in good agreement with data from 16 
Table 1

Some references on methodology

Beresnev and AtKinson (1997, 1998a), Boore (1983, 1984, 1989b, 1996, 2000),

Boore and Joyner (1984), CAMpbell (1999), CARTwright and Longuet-Higgins (1956),

Correig (1996), Erdik and Durukal (2001), Ghosh (1992), Hanks and McGuire (1981), Herrmann (1985), Joyner (1984, 1995), Joyner and Boore (1988), KAmAe and Irikura (1992), Kamae et al. (1998), Koyama (1997), LAm et al. (2000), LiaO and Jin (1995), LiU and PeZeshK (1998, 1999), LOH and YeH (1988), Miles and Ho (1999), ÓlafsSon and SigbJörnsson (1999), Ou and HerrmanN (1990a, 1990b), Papageorgiou and Aki (1983a), Pezeshr et al. (2001), Rathje et al. (1998), Sabetta and Pugliese (1996), ŞAFAK and Boore (1988), Schneider et al. (1991), ShAPIRA and VAN Eck (1993),

Silva (1992), Silva and LeE (1987), Silva et al. (1988, 1990, 1997), TAMura et al. (1991),

WENNERBERG (1990), Yu et al.

earthquakes. I generalized their work to allow for arbitrarily complex models, extended it to the simulation of time series, and considered many measures of ground motions, the most important of which are response spectra (BOORE, 1983). The underlying simplicity of the method, however, remains unchanged. The essence of the method is shown in Figure 1: The top of the figure shows the spectrum of the ground motion at a particular distance and site condition for magnitude 5 and 7 earthquakes, based on a standard seismological model; by assuming that this motion is distributed with random phase over a time duration related to earthquake size and propagation distance, the time series shown in the bottom of the figure are produced.

The essential ingredient for the stochastic method is the spectrum of the ground motion - this is where the physics of the earthquake process and wave propagation are contained, usually encapsulated and put into the form of simple equations. Most of the effort in developing a model is in describing the spectrum of ground motion. As is traditional, I find it convenient to break the total spectrum of the motion at a site $\left(Y\left(M_{0}, R, f\right)\right)$ into contributions from earthquake source $(E)$, path $(P)$, site $(G)$, and instrument or type of motion $(I)$, so that

$$
Y\left(M_{0}, R, f\right)=E\left(M_{0}, f\right) P(R, f) G(f) I(f),
$$

where $M_{0}$ is the seismic moment, introduced into seismology in 1966 by K. AKI (AKI, 1966). I usually use moment magnitude $\mathbf{M}$ rather than seismic moment as a more familiar measure of earthquake size; there is a unique mapping between the two:

$$
\mathbf{M}=\frac{2}{3} \log M_{0}-10.7
$$

(HANKS and KANAMORI, 1979).

Seismic moment has a number of advantages as the predictor variable for earthquake size in applications:

- It is the best single measure of overall size of an earthquake and is not subject to saturation.

- It can be determined from ground deformation or from seismic waves. 

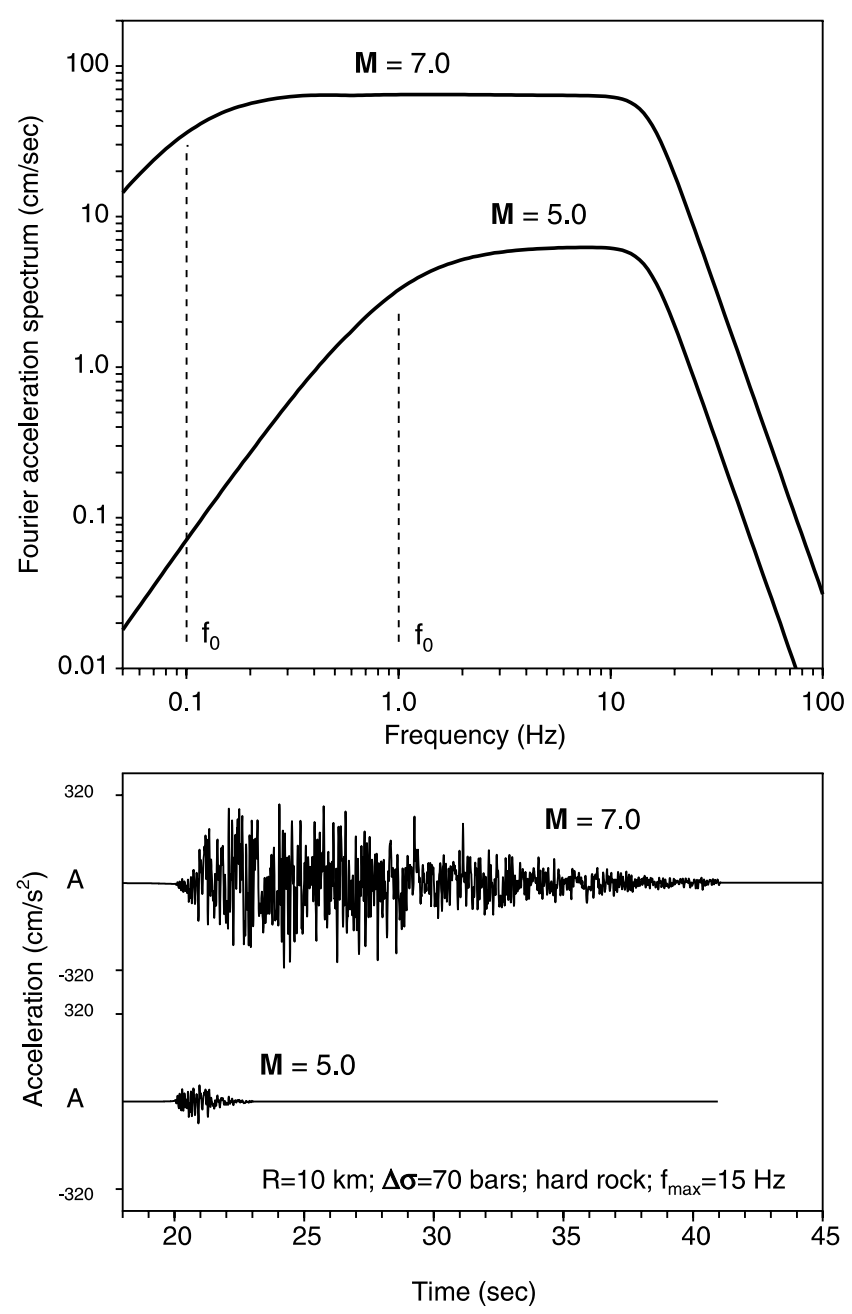

Figure 1

Basis for stochastic method. Radiated energy described by the spectra in the upper part of the figure is assumed to be distributed randomly over a duration equal to the inverse of the lower corner frequency $\left(f_{0}\right)$. Each time series is one realization of the random process for the actual spectrum shown. When plotted on a $\log$ scale, the levels of the low-frequency part of the spectra are directly proportional to the logarithm of the seismic moment and thus to the moment magnitude. Various peak ground-motion parameters (such as response spectra, instrument response, and velocity and acceleration) can be obtained by averaging the parameters computed from each member of a suite of acceleration time series or more simply by using random vibration theory, working directly with the spectra. The examples in this figure came from an actual simulation and are not sketched in by hand.

- It can be estimated from paleoseismological studies.

- It can be related to slip rates on faults.

- It is the variable of choice for empirically and theoretically based equations for the prediction of ground motions. 
By separating the spectrum of ground motion into source, path, and site components, the models based on the stochastic method can be easily modified to account for specific situations or to account for improved information about particular aspects of the model.

\section{The Source $\left(E\left(M_{0}, f\right)\right)$}

Both the shape and the amplitude of the source spectrum must be specified as a function of earthquake size. This is the most critical part of any application of the method. References given later should be consulted to see how various authors have approached this issue. The most commonly used model of the earthquake source spectrum is the $\omega$-square model, a term coined by AKI (1967). Figure 2 shows this spectrum for earthquakes of moment magnitude 6.5 and 7.5. The scaling of the spectra from one magnitude to another is determined by specifying the dependence of the corner frequency $f_{0}$ on seismic moment. AKI (1967) recognized that assuming similarity in the earthquake source implies that

$$
M_{0} f_{0}^{3}=\text { constant }
$$

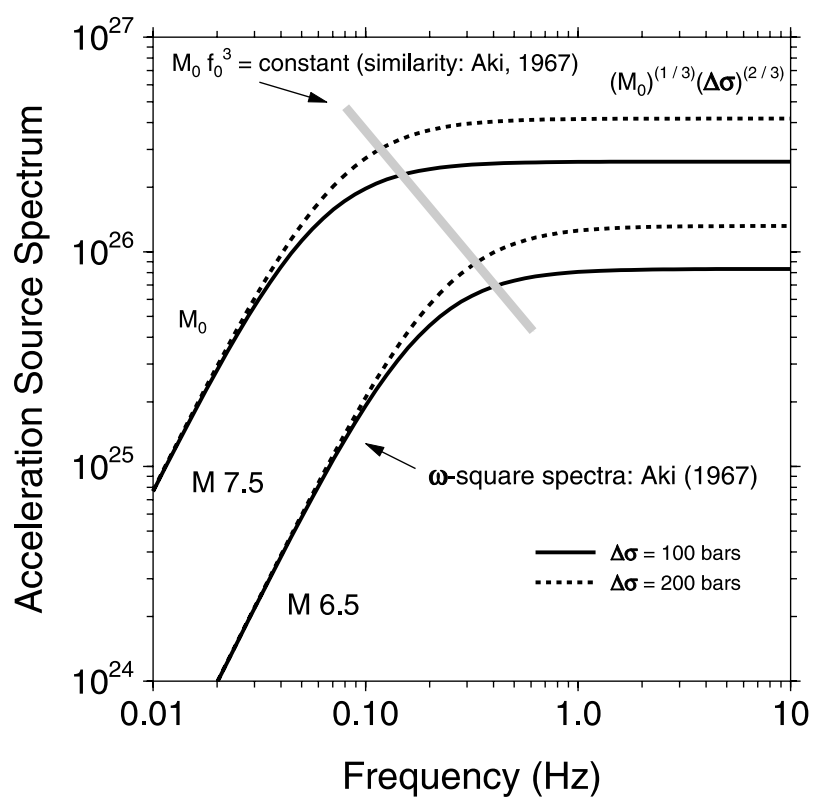

Figure 2

Source scaling for single-corner-frequency $\omega$-square spectral shape. For constant stress $\operatorname{drop} M_{0} f_{0}^{3}$ is a constant (AKI, 1967), and this dependence of the corner frequency $f_{0}$ on the moment $M_{0}$ (given by the shaded line) determines the scaling of the spectral shapes. 
where the constant can be related to the stress drop $(\Delta \sigma)$. Following BRUNE (1970, 1971), the corner frequency is given by the following equation:

$$
f_{0}=4.9 \times 10^{6} \beta_{s}\left(\Delta \sigma / M_{0}\right)^{1 / 3},
$$

where $f_{0}$ is in $\mathrm{Hz}, \beta_{s}$ (the shear-wave velocity in the vicinity of the source) in $\mathrm{km} / \mathrm{s}, \Delta \sigma$ in bars, and $M_{0}$ in dyne-cm.

Although the $\omega$-square model is widely used, in practice a variety of other models have been used with the stochastic method. Figure 3 shows a number of those that have been used to predict ground motions in eastern North America. It turns out that the source spectra for all of the models can be given by the following equation:

$$
E\left(M_{0}, f\right)=C M_{0} S\left(M_{0}, f\right),
$$

where $C$ is a constant, given below, and $S\left(M_{0}, f\right)$ is the displacement source spectrum, given by the equation

$$
S\left(M_{0}, f\right)=S_{a}\left(M_{0}, f\right) \times S_{b}\left(M_{0}, f\right),
$$

and $S_{a}, S_{b}$ for the various models shown in Figure 3 are given in Table 2 . The moment dependence of the two factors $S_{a}$ and $S_{b}$ is given by the relations between the

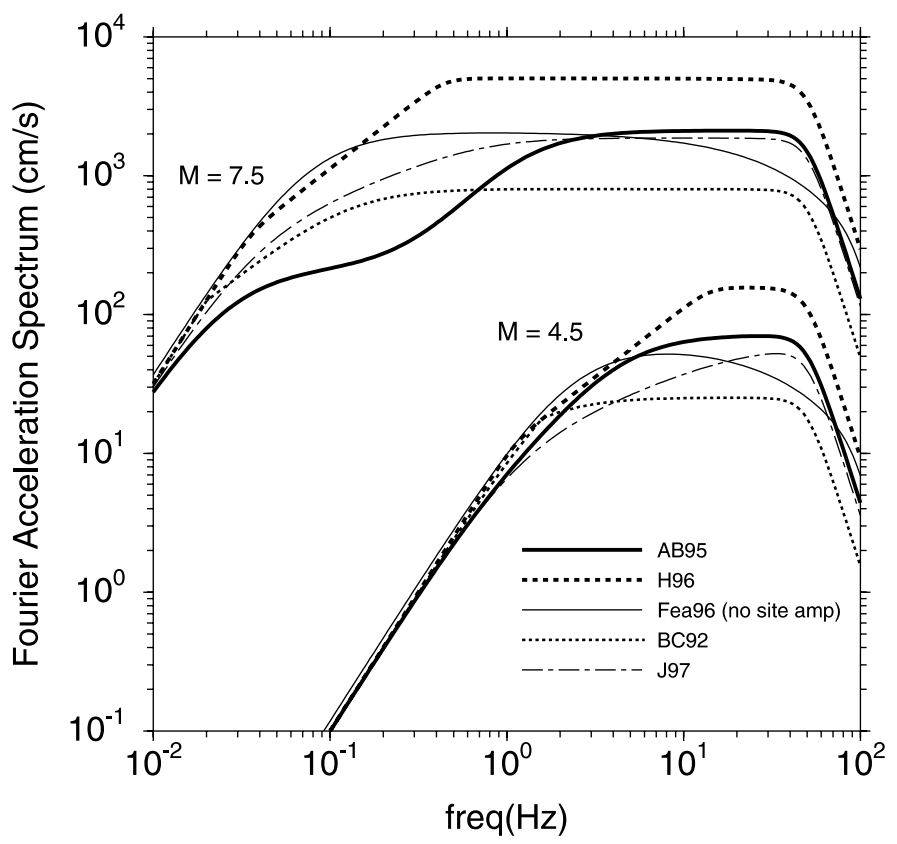

Figure 3

Fourier spectrum of acceleration at $\mathrm{R}=1 \mathrm{~km}$, according to the source spectral models given in Tables 2 and 3 (from ATKINSON and BOORE, 1998). (The roll-off at high frequencies is produced by using equation (19) with $f_{\max }=50 \mathrm{~Hz}$ ). 
Table 2

Shape of source spectral $\left(S(f)=S_{a}(f) * S_{b}(f)\right)$

\begin{tabular}{ccc}
\hline Model $^{\dagger}$ & $S_{a}$ & $S_{b}$ \\
\hline BC92 & $f<f_{a}: 1$ & $\frac{1}{\left(1+\left(f / f_{b}\right)^{2}\right)^{1 / 2}}$ \\
AB95 & $f \geq f_{a}: f_{a} / f$ & 1 \\
Fea96 & $\frac{1-\epsilon}{1+\left(f / f_{a}\right)^{2}}+\frac{1}{1+\left(f / f_{b}\right)^{2}}$ & 1 \\
H96 & $\frac{1}{1+\left(f / f_{a}\right)^{2}}$ & $\frac{1}{\left(1+\left(f / f_{a}\right)^{8}\right)^{1 / 8}}$ \\
J97 & $\frac{1}{\left(1+\left(f / f_{a}\right)^{2}\right)^{3 / 4}}$ & $\frac{1}{\left(1+\left(f / f_{b}\right)^{2}\right)^{1 / 4}}$ \\
AS00 & $\frac{1-\epsilon}{1+\left(f / f_{a}\right)^{2}}+\frac{\epsilon}{1+\left(f / f_{b}\right)^{2}}$ & 1 \\
\hline
\end{tabular}

$\dagger$ The references to the models are as follows: BC92 = BOATwRIGHT and CHOY (1992); AB95 = ATKINSON and Boore (1995); Fea96 = Frankel et al. (1996); H96 = HADDON (1996); J97 = JOYNER (1997), as modified in a written communication to D. Boore; AS00 = ATKINSON and Silva (2000) for California.

* This is the $\omega$-square model.

corner frequencies $f_{a}$ and $f_{b}$ appearing in the factors and the seismic moment, as shown in Table 3 (which also contains the scaling for the ATKINSON and SILVA (2000) model for California; a number of illustrations later in the paper use their model). The constant $C$ in equation (5) is given by

$$
C=\left\langle R_{\Theta \Phi}\right\rangle V F /\left(4 \pi \rho_{s} \beta_{s}^{3} R_{0}\right),
$$

where $\left\langle R_{\Theta \Phi}\right\rangle$ is the radiation pattern, usually averaged over a suitable range of azimuths and take-off angles (BOORE and BOATwRIGHT, 1984), $V$ represents the partition of total shear-wave energy into horizontal components $(=1 / \sqrt{2}), F$ is the effect of the free surface (taken as 2 in almost all applications, which strictly speaking

Table 3

Corner frequencies and moment ratios

\begin{tabular}{cccc}
\hline Model & $\log f_{a}$ & $\log f_{b}$ & $\log \epsilon$ \\
\hline BC92 & $\mathbf{M} \geq 5.3:^{\dagger} 3.409-0.681 \mathbf{M}$ & $1.495-0.319 \mathbf{M}$ & - \\
& $\mathbf{M}<5.3: 2.452-0.5 \mathbf{M}$ & $2.452-0.5 \mathbf{M}$ & - \\
AB95 & $\mathbf{M} \geq 4.0:^{\ddagger} 2.41-0.533 \mathbf{M}$ & $1.43-0.188 \mathbf{M}$ & $2.52-0.637 \mathbf{M}$ \\
& $\mathbf{M}<.0: 2.678-0.5 \mathbf{M}$ & $2.678-0.5 \mathbf{M}$ & 0.0 \\
Fea96* & $2.623-0.5 \mathbf{M}$ & - & - \\
H96 & $2.3-0.5 \mathbf{M}$ & $3.4-0.5 \mathbf{M}$ & - \\
J97 & $2.312-0.5 \mathbf{M}$ & $3.609-0.5 \mathbf{M}$ & - \\
AS00 & $\mathbf{M} \geq 2.4:^{\dagger} 2.181-0.496 \mathbf{M}$ & $2.41-0.408 \mathbf{M}$ & $0.605-0.255 \mathbf{M}$ \\
& $\mathbf{M}<2.4:$ & $1.431-0.5(\mathbf{M}-2.4)$ & 0.0 \\
& $1.431-0.5(\mathbf{M}-2.4)$ & & \\
\hline
\end{tabular}

$\uparrow$ The specified magnitude corresponds to the point at which $f_{a}=f_{b}$.

\$ The specified magnitude corresponds to the point at which $\epsilon=1.0$.

${ }^{*}$ This is the $\omega$-square model, for which $\log f_{0}=1.341+\log \left(\beta(\Delta \sigma)^{1 / 3}\right)-0.5 \mathbf{M}$, with $\beta=3.6 \mathrm{~km} / \mathrm{s}$ and $\Delta \sigma=150$ bars. 
is only correct for SH waves), $\rho_{s}$ and $\beta_{s}$ are the density and shear-wave velocity in the vicinity of the source, and $R_{0}$ is a reference distance, usually set equal to $1 \mathrm{~km}$. In applications, care must be taken if mixed units are used. For example, if ground motion is to be in $\mathrm{cm}$ and $\rho_{s}, \beta_{s}$, and $R_{0}$ are in units of $\mathrm{gm} / \mathrm{cc}, \mathrm{km} / \mathrm{s}$ and $\mathrm{km}$, respectively, then $C$ in equation (7) should be multiplied by the factor $10^{-20}$. It is probably safer to convert all quantities into common units.

\section{The Path $(P(R, f)$, duration $)$}

Now that the source has been specified, it remains to discuss the other components of the process that affect the spectrum of motion at a particular site. The next component is the path effect. For some applications involving a specific path from source to site it might be desirable to convolve the radiation from the source with theoretically calculated path effects. An example of calculated path response is shown in Figure 4 for a four-layer model of the crust in the central United States. The response is complicated because of the critical-angle arrivals and reverberations of the waves. Even though complicated, however, the response is probably simpler than reality because the crust may not be laterally uniform and because scattering has not been included. For most applications it is advisable to represent the effects of the path by simple functions that account for geometrical spreading, attenuation (combining intrinsic and scattering attenuation), and the general increase of duration with distance due to wave propagation and scattering.

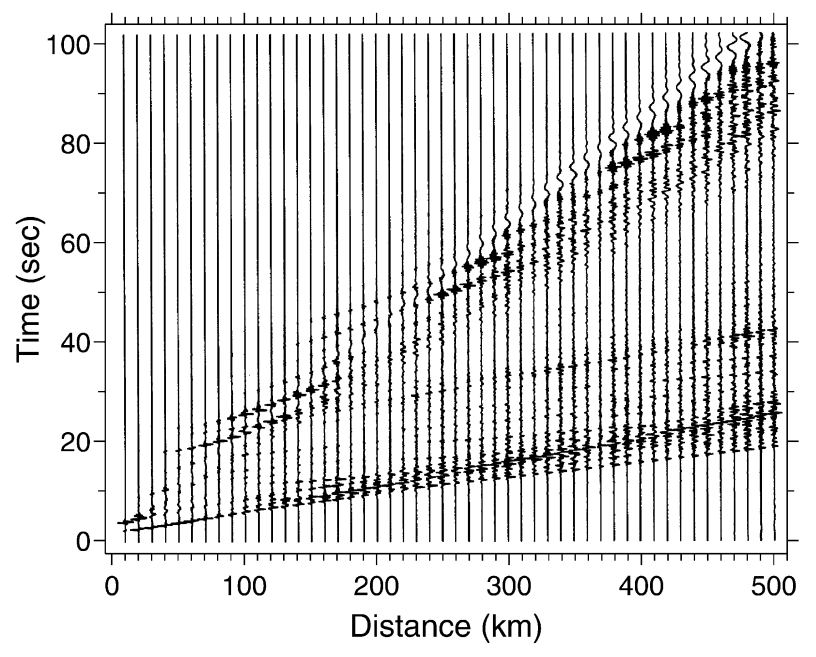

Figure 4

Synthetic seismograms for a 4-layer model of the crust in the central United States, showing the complexity of the waveforms and duration due to reverberations within the crust (written commun., R. HERrmanN, 2000). 
The simplified path effect $P$ is given by the multiplication of the geometrical spreading and $Q$ functions

$$
P(R, f)=Z(R) \exp \left[-\pi f R / Q(f) c_{Q}\right],
$$

where $c_{Q}$ is the seismic velocity used in the determination of $Q(f)$, and the geometrical spreading function $Z(R)$ is given by a piecewise continuous series of straight lines:

$$
Z(R)= \begin{cases}\frac{R_{0}}{R} & R \leq R_{1} \\ Z\left(R_{1}\right)\left(\frac{R_{1}}{R}\right)^{p_{1}} & R_{1} \leq R \leq R_{2} \\ \vdots & \\ Z\left(R_{n}\right)\left(\frac{R_{n}}{R}\right)^{p_{n}} & R_{n} \leq R\end{cases}
$$

In applications, $R$ is usually taken as the closest distance to the rupture surface, rather than the hypocentral distance. In some applications it may be appropriate to include a period and/or moment dependent "pseudo-depth" $h$ in a manner consistent with the effectively point-source models used in fitting empirical strong-motion data. For example, following BOoRE et al. (1997) $R$ would be given by $R=\sqrt{D^{2}+h^{2}}$, where $D$ is the closest distance to the vertical projection of the rupture surface onto the ground surface, and $h$ is taken from the empirical results in BOoRE et al. (1997). Other empirically-based prediction equations use different relations to determine the distance - see the review by CAMPBELL (2002) - but the idea is the same. By defining $R$ in this way rather than as hypocentral distance, the method is more applicable to extended ruptures. As an example of $Z(R)$, Figure 5 shows the three-segment geometrical spreading operator used in ATKINSON and BOORE's (1995) predictions of ground motions in eastern North America. For this example, $R_{0}=1, R_{1}=70$, $p_{1}=0.0, R_{2}=130$, and $p_{2}=0.5$.

The form of the attenuation operator is motivated by K. Aki's compilation of seismic attenuation $Q$ shown in Figure 6. As a simple way of capturing the variation of $Q$, the attenuation operator is made up of three piecewise-continuous line segments (Fig. 7). The outer lines are specified by slopes and intercepts at specified reference frequencies, and the middle line joins the outer lines between frequencies $f t 1$ and $f t 2$. In applications the various parameters describing the attenuation operator can be obtained from analysis of weak-motion data, if available. If determined from data, it is important to keep in mind the tradeoffs between geometrical spreading and attenuation. Both functions are needed in fitting data, and for consistency, the same functions must be used in applications. An example of the combined path effect is shown in Figure 8, which compares observed spectral amplitudes as a function of distance with geometrical spreading and attenuation operators fit to the data. In this case the geometrical spreading function is that shown in Figure 5, and the $Q$ function is given by $Q=680 f^{0.38}$, which is the s2 branch in Figure 6 (the data were not sufficient to determine the longer-period s1 branch). 


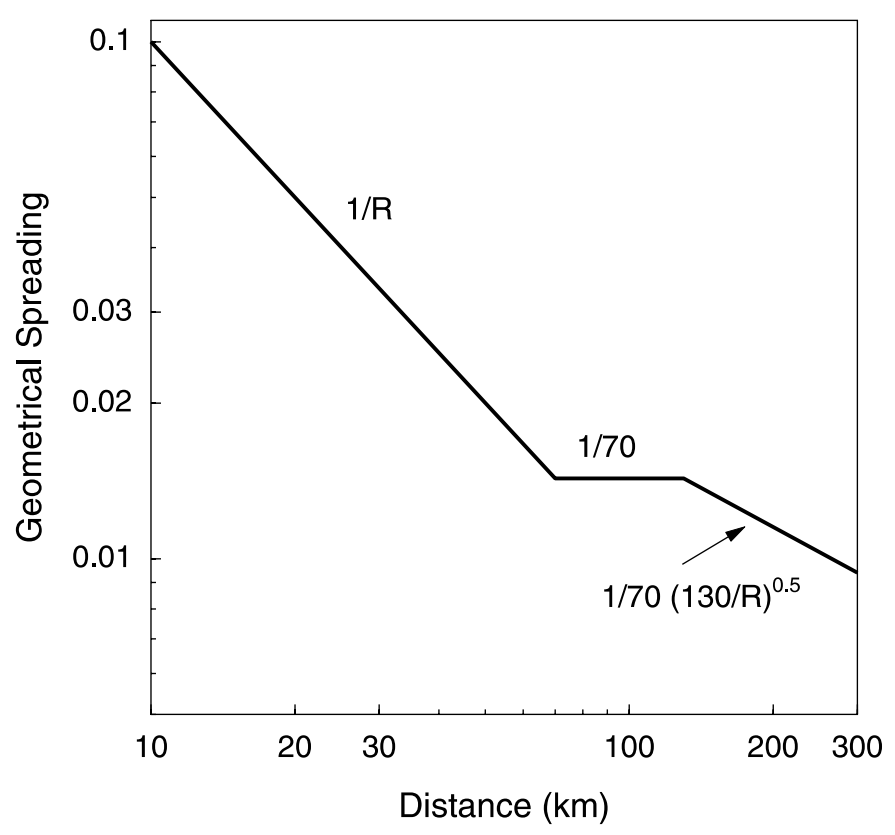

Figure 5

The geometrical spreading function used in applications in central and eastern North America by AtKinson and Boore (1995) and Frankel et al. (1996).

The distance-dependent duration is an important function, for the peak motions decrease with increasing duration, all other things being equal. Although the Fourier amplitude spectrum of the ground motion (equation (1)) is not dependent on the duration, I include a discussion of duration here because it is a function of the path, as well as the source; the way it is used in the calculations of ground motion is given later. The ground-motion duration $\left(T_{g m}\right)$ is the sum of the source duration, which is related to the inverse of a corner frequency (e.g., $0.5 / f_{a}$ for the AB95 and $1 / f_{a}$ for the Fea96 models in Tables 2 and 3) and a path-dependent duration. Empirical observations and theoretical simulations suggest that the path-dependent part of the duration can be represented by a connected series of straight-line segments. The function used in ATKINSON and BOORE (1995) is shown in Figure 9, along with the data from which the function was determined.

\section{The Site $(G(f))$}

In the strictest sense, the modification of seismic waves by local site conditions is part of the path effect. Because local site effects, however, are largely independent of the distance traveled from the source (except for nonlinear effects for which the amplitudes of motion are important), it is convenient to separate site and path 


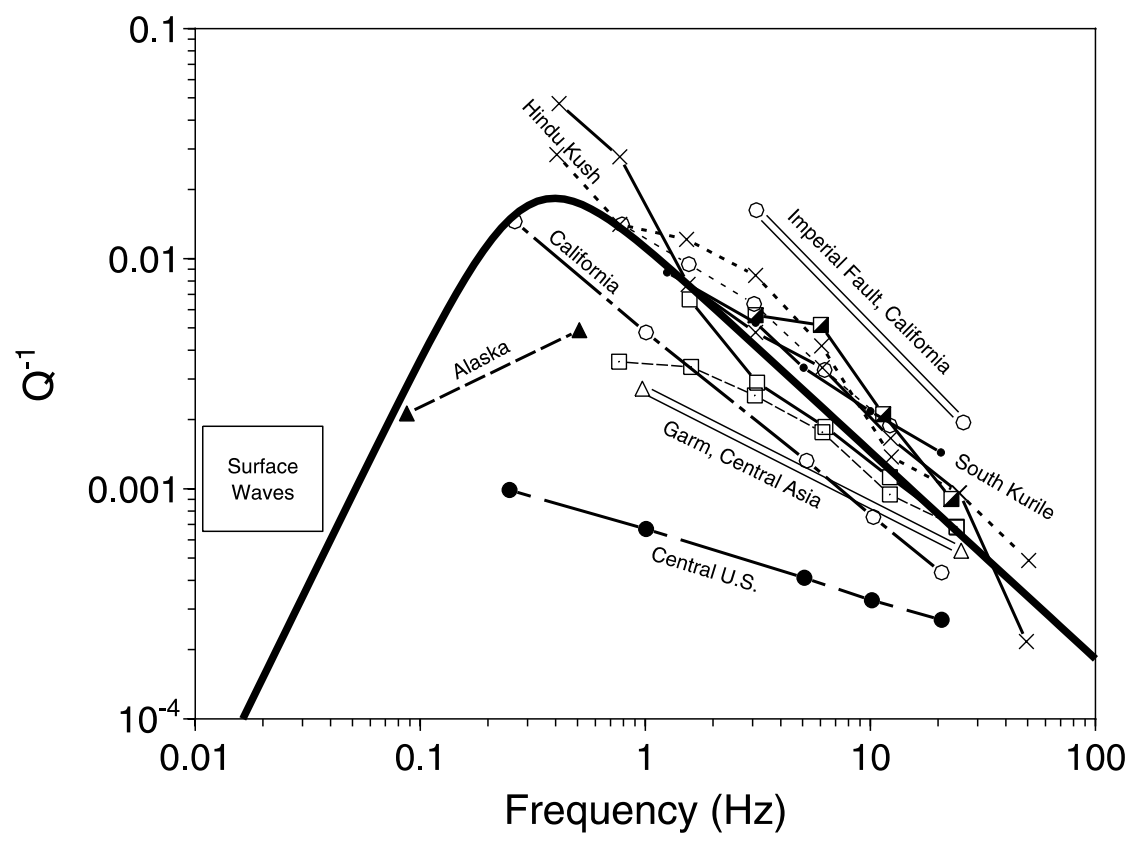

Figure 6

Observed inverse shear-wave $Q$ from Aki (AKI, 1980, summarized by CoRMIER, 1982); the heavy solid line is an "eyeball" average of the observations. (Figure modified from BooRE, 1984.)

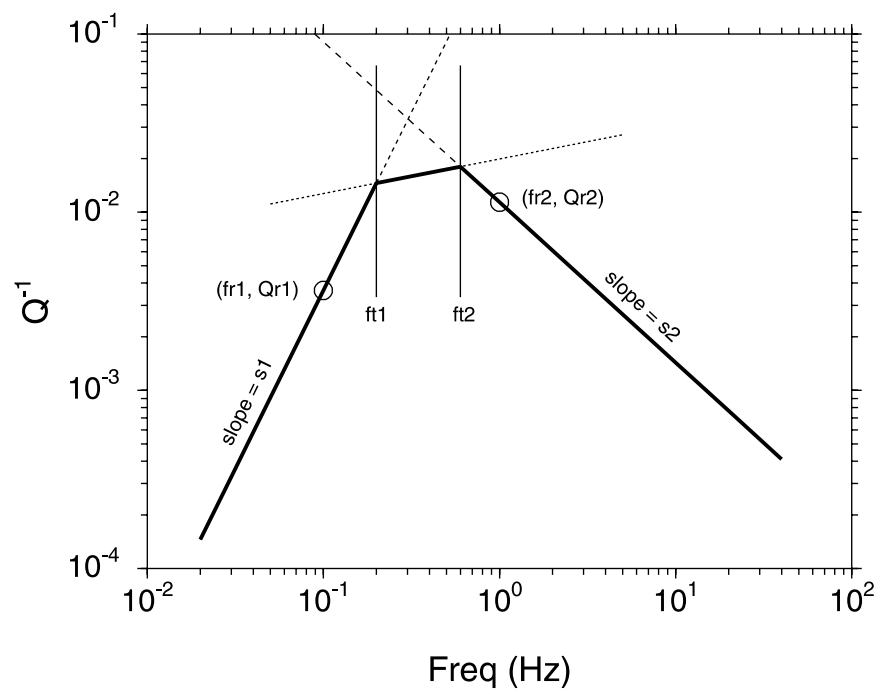

Figure 7

Illustration of the specification of $Q(f)$ : it is made up of three lines in $\log -\log$ space. The lines shown are an approximation of the $Q(f)$ function shown in the previous figure. 

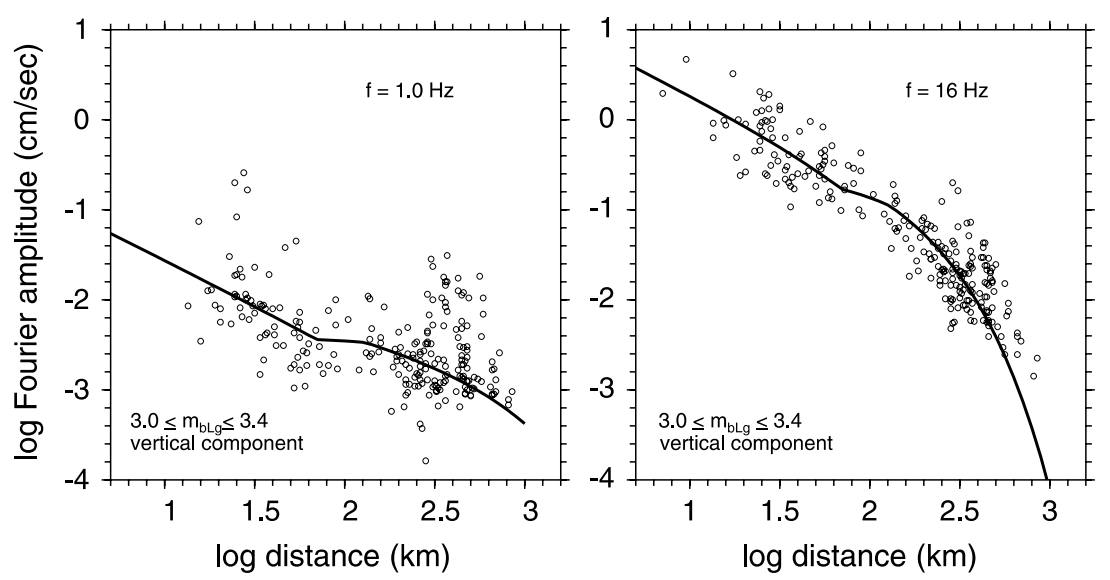

Figure 8

Observed attenuation of motions with distance in eastern North America for a narrow range of magnitudes (data: written commun. from G. ATKINSON, 2000), along with the combination of geometrical spreading and whole path attenuation used by ATKINSON and BOORE (1995) and FrANKEL et al. (1996) in simulating ground motions in central and eastern North America.

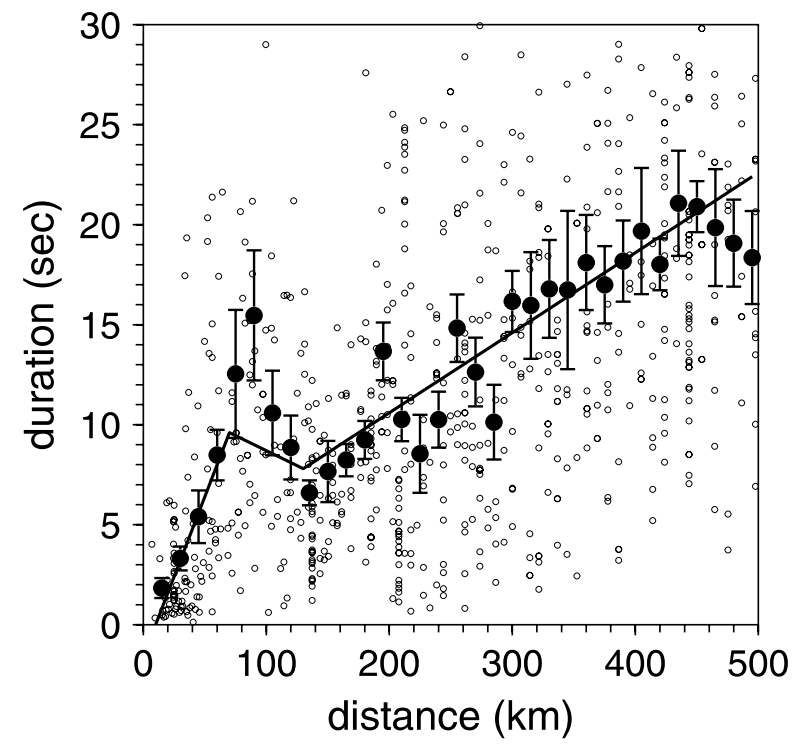

Figure 9

Observed duration (after subtracting source duration) from earthquakes in eastern North America. The data were used by ATKINSON (1993) and ATKINSON and BOORE (1995) to define path-dependent durations for use in stochastic method simulations. The solid circles are averages within $15-\mathrm{km}$-wide bins, and the error bars are plus and minus one standard error of the mean. The three-part solid line is the duration function used by ATKINSON and BOORE (1995) in simulations of ground motions in eastern North America. 
effects. Much effort can go into accounting for the modifications of the ground motion due to local site geology. This is a situation where site-specific effects might best be used. On the other hand, in many cases the simulations from the stochastic method are intended to be used for the prediction of motion at a generic site - such as a generic rock or a generic soil site. In such cases, a simplified function can be used to describe the frequency-dependent modifications of the seismic spectrum. I find it convenient to separate the amplification $(A(f))$ and attenuation $(D(f))$, as follows:

$$
G(f)=A(f) D(f) .
$$

The amplification function $A(f)$ is usually relative to the source unless amplitude variations due to wave propagation, separate from the geometrical spreading, have been accounted for. In contrast, the diminution function $D(f)$ is used to model the path-independent loss of energy (the path-dependent part is modeled by the exponential function in equation (8)). It is important in applications to be specific about the reference conditions for the $A$ and $D$ functions. In general, $G$ can be a function of the amplitude of shaking, but I do not account for nonlinear effects in my method, preferring to compute rock motions using a linear model and account for nonlinear effects as part of an additional site-response calculation. W. Silva, however, has incorporated nonlinear effects into his version of the stochastic method (SILVA et al., 1991).

The starting point for deriving the amplification $A(f)$ is a function of shear-wave velocity vs. depth. Figure 10 shows such a function for a generic rock site appropriate for coastal California. The top $100 \mathrm{~m}$ is based on averaging of travel times measured in boreholes, while the deeper parts of the curve are based on judgment and a few data (BOORE and JOYNER, 1997). The amplification $A(f)$ can be given by wave-calculation solutions that account for reverberations, or approximately and more simply by assuming that the amplification of the waves is given by the square root of the impedance ratio between the source and the surface. The algorithm is the following:

$$
A(f(z))=\sqrt{Z_{s} / \bar{Z}(f)},
$$

where the seismic impedance near the source $\left(Z_{s}\right)$ is given by

$$
Z_{s}=\rho_{s} \beta_{s},
$$

and $\rho_{s}$ and $\beta_{s}$ are the density and shear-wave velocity near the source. $\bar{Z}(f)$ is an average of near-surface seismic impedance; it is a function of frequency because it is a time-weighted average from the surface to a depth equivalent to a quarter wavelength:

$$
\bar{Z}(f)=\int_{0}^{t(z(f))} \rho(z) \beta(z) d t / \int_{0}^{t(z(f))} d t
$$




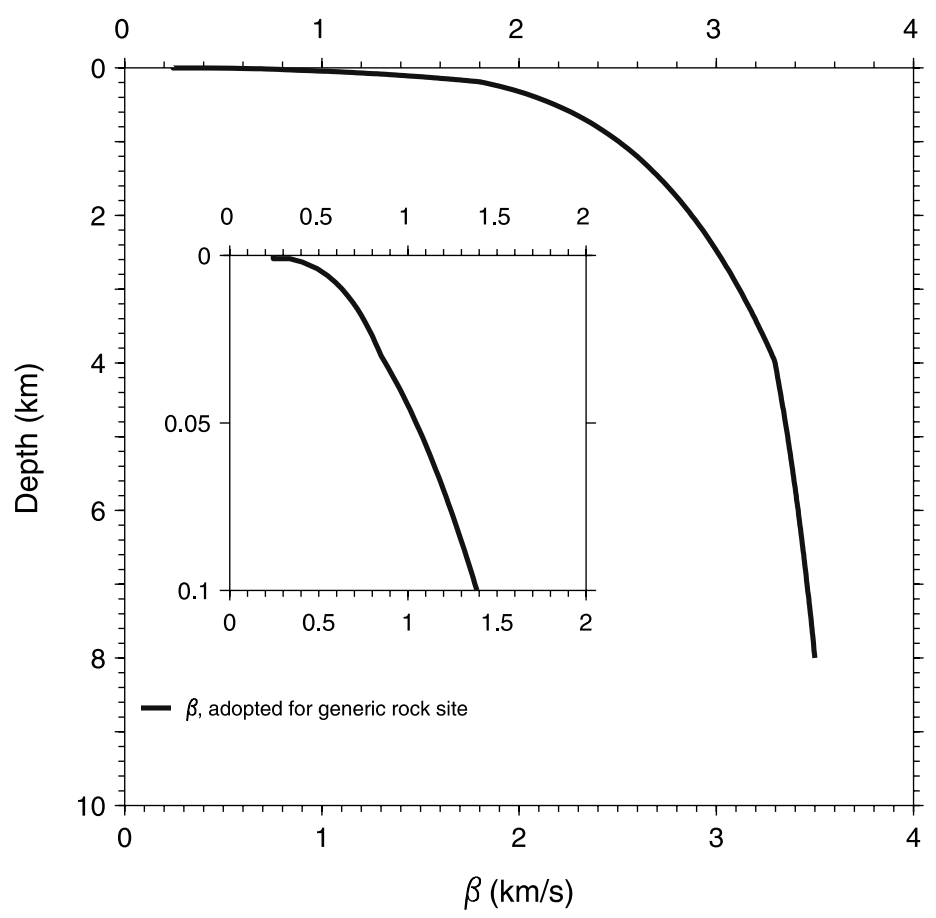

Figure 10

$S$-wave velocity versus depth used by BOORE and JOYNER (1997) for computing amplifications on generic "soft" rock sites (adapted from BOORE and JOYNER, 1997.)

in which the upper limit of the integral is the time for shear waves to travel from depth $z(f)$ to the surface. The depth is a function of frequency and is chosen such that $z$ is a quarter-wavelength for waves traveling at an average velocity given by $\bar{\beta}=z(f) / \int_{0}^{z(f)}[1 / \beta(z)] d z$. The condition of a quarter-wavelength $z=(1 / 4) \bar{\beta} / f$ then yields the following implicit equation for $z(f)$ :

$$
f(z)=1 /\left[4 \int_{0}^{z(f)} \frac{1}{\beta(z)} d z\right] .
$$

In practice, it is easiest to compute $f$ and $\bar{Z}$ for a given $z$. By changing variables from time to depth, equation (13) becomes

$$
\bar{Z}(f)=\int_{0}^{z(f)} \rho(z) d z / \int_{0}^{z(f)} \frac{1}{\beta(z)} d z .
$$

Equation (15) can be simplified to 


$$
\bar{Z}(f)=\bar{\rho} \bar{\beta}
$$

where

$$
\bar{\rho}=\frac{1}{z(f)} \int_{0}^{z(f)} \rho(z) d z
$$

and

$$
\bar{\beta}=z(f)\left[\int_{0}^{z(f)} \frac{1}{\beta(z)} d z\right]^{-1} .
$$

Figure 11 compares the amplification computed using equation (11) for the generic rock velocity profile in Figure 10 and wave propagation for two angles of incidence.

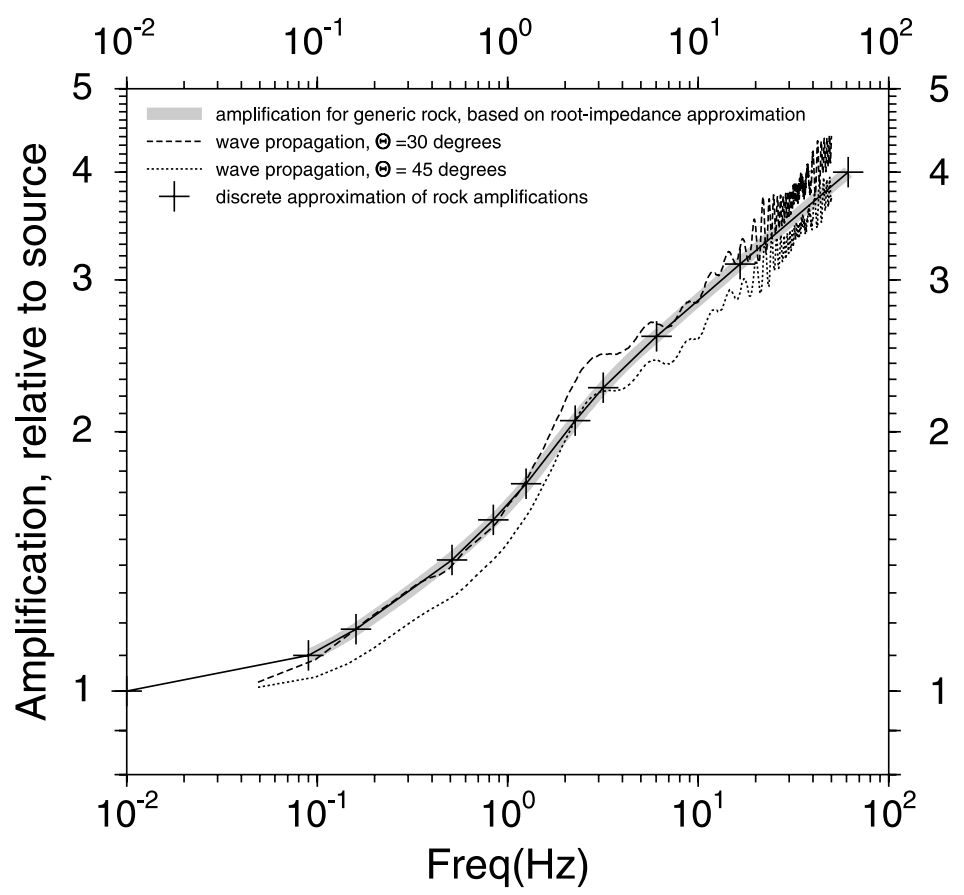

Figure 11

Amplification vs. frequency. The wide shaded line is computed using the root-impedance approximation and the velocity profile shown in the preceeding figure. The results from plane $S H$ waves incident at the base of a $8-\mathrm{km}$ thick stack of constant-velocity layers (with $Q=10000$ ) closely approximating the continuous shear-wave velocity in the previous figure are shown by the light lines for angles of incidence of 30 and 45 degrees; the results were computed from the Haskell matrix method, as implemented by program Rattle by C. Mueller. The segmented-line function used in the stochastic method is given by lines joining the plus symbols. (Adapted from BOore and JOYNER, 1997.) 
For application, it is convenient to approximate the amplification by a series of connected line segments; these are also shown in Figure 11.

The attenuation, or diminution, operator $D(f)$ in equation (10) accounts for the path-independent loss of high-frequency in the ground motions. This loss may be due to a source effect, as suggested by PAPAGEORGIOU and AKI (1983b) or a site effect, as suggested by a number of authors, including HANKS (1982), or by a combination of these effects. If a source effect, $D$ may also depend on the size of the earthquake. It is not my intention to argue for a particular cause, but only to point out that a simple multiplicative filter can account for the diminution of the high-frequency motions. Two filters are in common use: the $f_{\max }$ filter

$$
D(f)=\left[1+\left(f / f_{\max }\right)^{8}\right]^{-1 / 2},
$$

(HANKS, 1982; BOORE, 1983), and the $\kappa_{0}$ filter

$$
D(f)=\exp \left(-\pi \kappa_{0} f\right),
$$

(ANDERSON and Hough, 1984). Of course, both filters can be combined in an application.

The combined effect of amplification and attenuation for a series of diminution parameters $\kappa_{0}$ is shown in Figure 12 for a generic rock site in coastal California. Comparisons with data suggest that $\kappa_{0}$ near 0.04 is appropriate (BOORE and JOYNER, 1997). Filters for other types of site geology can be obtained by combining the results

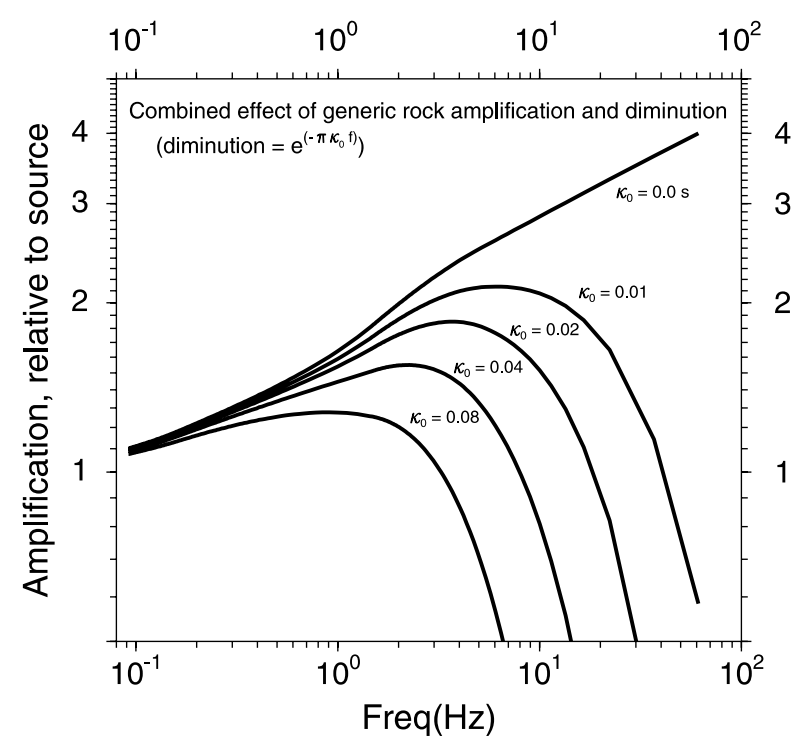

Figure 12

Combined effect of the site amplification in the previous figure and path-independent diminution. (Adapted from BOORE and JOYNER, 1997.) 
in Figure 12 with the site effects from empirical attenuation curves. The results are shown in Figure 13 (for more detail, see Boore and Joyner, 1997).

\section{Accounting for Type of Ground Motion $(I(f))$}

The particular type of ground motion resulting from the simulation is controlled by the filter $I(f)$. If ground motion is desired, then

$$
I(f)=(2 \pi f i)^{n},
$$

where $i=\sqrt{-1}$ and $n=0,1$, or 2 for ground displacement, velocity, or acceleration, respectively. For the response of an oscillator, from which response spectra or WoodAnderson magnitudes can be derived,

$$
I(f)=\frac{-V f^{2}}{\left(f^{2}-f_{r}^{2}\right)-2 f f_{r} \zeta i},
$$

for an oscillator with undamped natural frequency $f_{r}$, damping $\zeta$, and gain $V$ (for computation of response spectra, $V=1$ ).

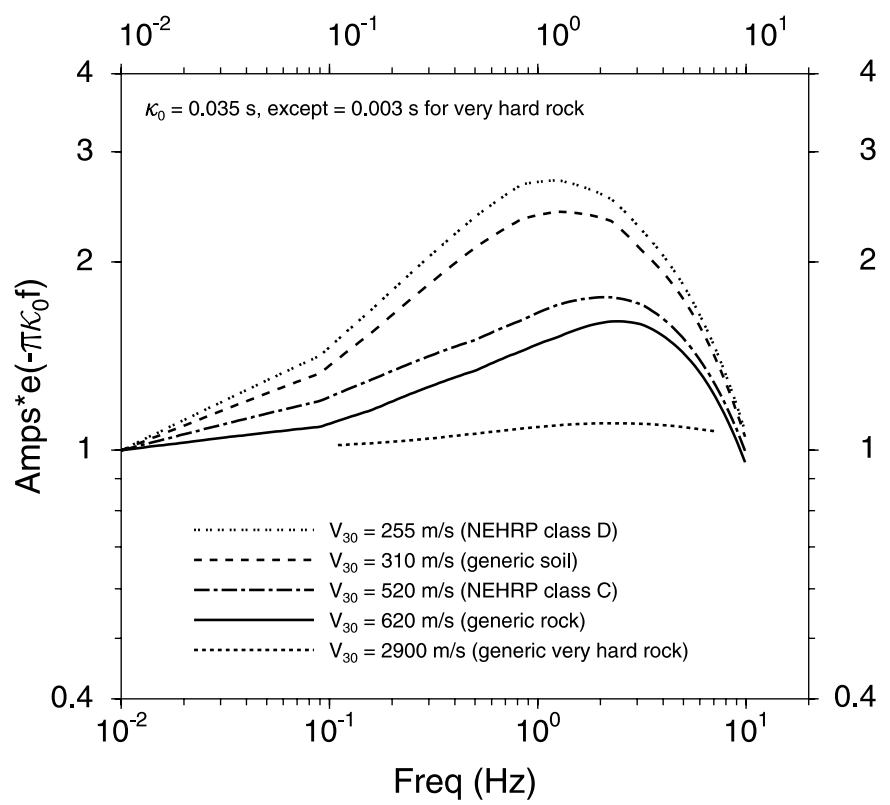

Figure 13

The product of Fourier spectral amplifications and the diminution factor $\exp \left(-\pi \kappa_{0} f\right)$ for various site conditions, as measured by the average shear-wave velocity in the upper $30 \mathrm{~m}$. (From BOORE and JOYNER, 1997.) 


\section{Integral Measures of Ground Motion}

Measures of ground motion based on some average of the motion over time or of the spectrum over frequency are sometimes used in seismic hazard (e.g., JIBSON, 1993; JiBSON et al., 1998; WiLSON, 1993). The most common of these may be the Arias intensity $\left(I_{x x}\right)$, defined as

$$
I_{x x} \equiv \frac{\pi}{2 g} \int_{0}^{t_{d}} a(t)^{2} d t
$$

where $g$ is the acceleration of gravity, $a$ is the ground acceleration, and $t_{d}$ is the duration of the motion (ARIAS, 1970). This intensity measure can be easily computed within the context of the stochastic method, as shown below.

\section{Obtaining Ground Motions}

Given the spectrum of motion at a site, there are two ways of obtaining ground motions: 1) time-domain simulation and 2) estimates of peak motions using random vibration theory.

\section{Simulations of Time Series}

Time-domain simulations are easy to obtain. This is illustrated in Figure 14 for an actual application, using the AS00 model as given in Tables 2, 3, and 4 (this model is used for all but the last of the remaining figures). White noise (Gaussian or uniform) is generated for a duration given by the duration of the motion (Fig. 14a); this noise is then windowed (Fig. 14b); the windowed noise is transformed into the frequency domain (Fig. 14c); the spectrum is normalized by the square-root of the mean square amplitude spectrum (Fig. 14d); the normalized spectrum is multiplied by the ground motion spectrum $Y$ (Fig. 14e); the resulting spectrum is transformed back to the time domain (Fig. 14f). SAFAK and BOORE (1988) show that the order of windowing and filtering is important; if the white noise is first filtered and then windowed the long-period level of the motion is distorted.

The shaping window applied to the noise (Fig. 14b) can be either a box window or a window that gives a more realistic shape for the acceleration time series (as will be shown shortly, the decision to use a shaped rather than a box window is based more on aesthetics than on differences in the derived ground-motion parameters). By studying a number of recorded motions, SARAGONI and HART (1974) found that the following function is a good representation of the envelope of acceleration time series: 

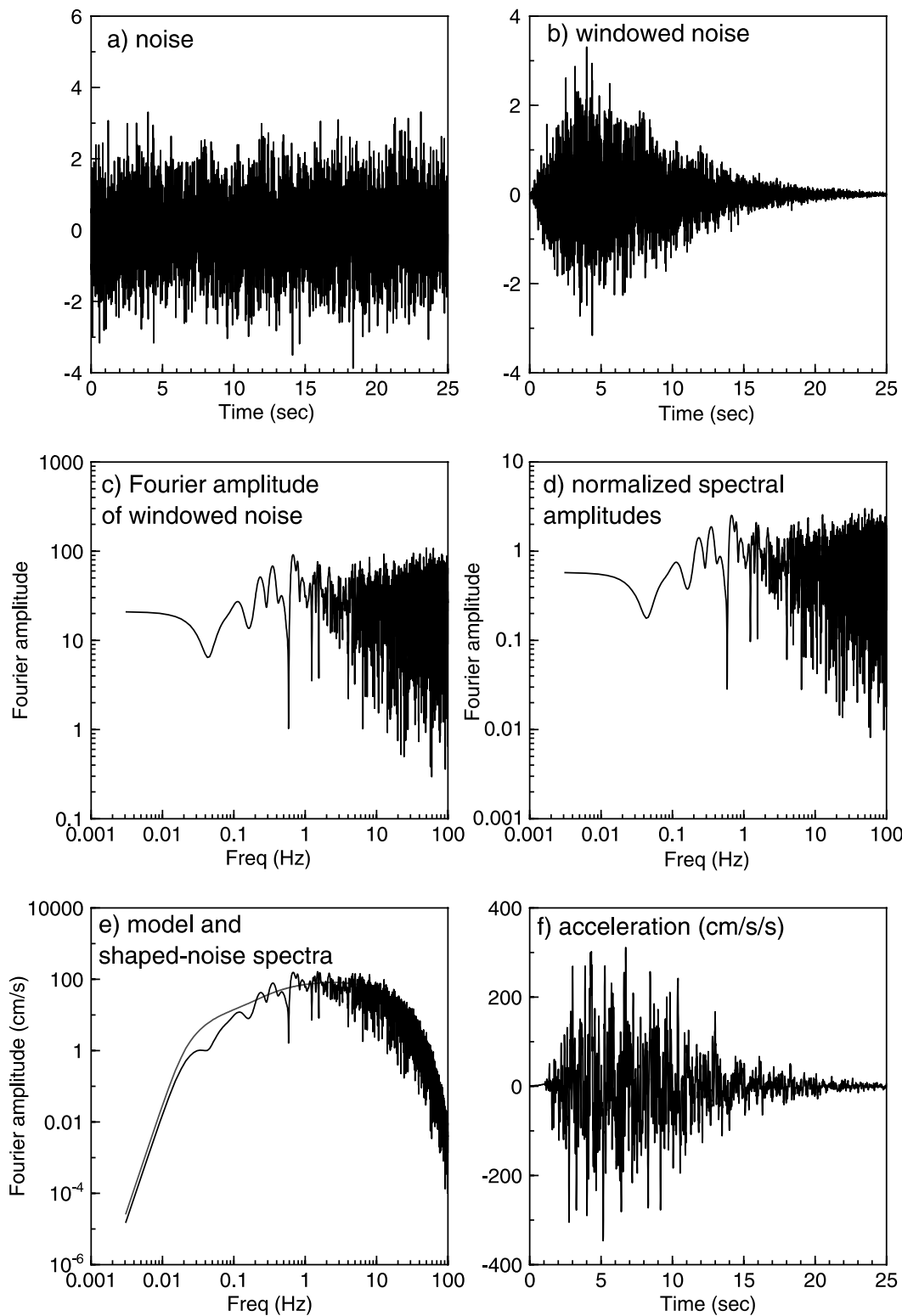

Figure 14

Basis of the time-domain procedure for simulating ground motions using the stochastic method. These are from an actual simulation, using the AS00 model as specified in Tables 2, 3, and 4. An acausal low-cut filter with a cut-off frequency of $0.02 \mathrm{~Hz}$ was applied to the acceleration time series. Various other measures of ground motion, such as peak velocity, peak displacement, Arias intensity, and response spectral amplitudes, can be computed from the simulated acceleration. 
Table 4

Parameters for ASOO model (from ATKINSON and SILVA, 2000)

- $\rho_{s}, \beta_{s}, V,\left\langle R_{\Theta \Phi}\right\rangle, F, R_{0}: 2.8,3.5,0.707,0.55,2.0,1.0$

- Geometrical spreading (including factors to insure continuity of function):

$r<40 \mathrm{~km}: 1 / r$

$40 \mathrm{~km} \leq r:(1 / 40)(40 / r)^{0.5}$

- $Q, c_{Q}: 180 f^{0.45}, 3.5 \mathrm{~km} / \mathrm{s}$

- Source duration: $0.5 / f_{a}$

- Path duration: $0.05 R$

- Site amplification: BoORE and Joyner (1997) generic rock (as shown in Figure 11).

- Site diminution parameters $\left(f_{\max }, \kappa\right): 100.0,0.030$.

$$
w\left(t ; \epsilon, \eta, t_{\eta},\right)=a\left(t / t_{\eta}\right)^{b} \exp \left(-c\left(t / t_{\eta}\right)\right),
$$

where the parameters $a, b$, and $c$ are determined such that $w(t)$ has a peak with value of unity when $t=\epsilon \times t_{\eta}$ and $w(t)=\eta$ when $t=t_{\eta}$ (see Fig. 15). The equations for $a$, $b$, and $c$ follow:

$$
\begin{gathered}
b=-(\epsilon \ln \eta) /[1+\epsilon(\ln \epsilon-1)], \\
c=b / \epsilon
\end{gathered}
$$

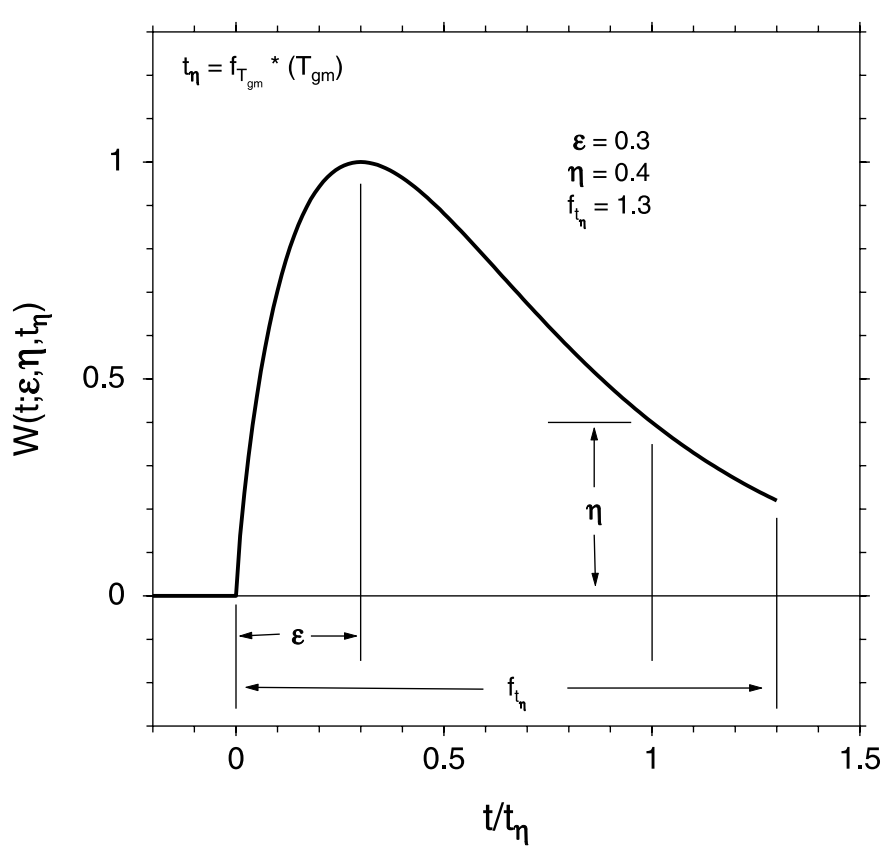

Figure 15

Exponential window and the variables controlling its shape. 
and

$$
a=(\exp (1) / \epsilon)^{b}
$$

As discussed in Boore (1983), a can also be chosen such that the integral of the square of $w(t)$ equals unity; this is appropriate if the spectrum of the windowed noise is not normalized so that it has a mean square amplitude of unity. The time $t_{\eta}$ is given by

$$
t_{\eta}=f_{T_{g m}} \times T_{g m}
$$

where $T_{g m}$ is the duration of ground motion. Based on SARAGONI and HART (1974), I use $\epsilon=0.2$ and $\eta=0.05$ in applications. I find a good comparison between response spectra computed using the box and exponential windows if $f_{T_{g m}}=2.0$. A comparison of accelerations derived from the box and the exponential windows is given in Figure 16. Also shown are the $5 \%$-damped pseudo-velocity response spectra obtained from averaging the response spectra computed from 640 simulated accelerations. It is clear that the response spectra obtained from the two windows are similar.

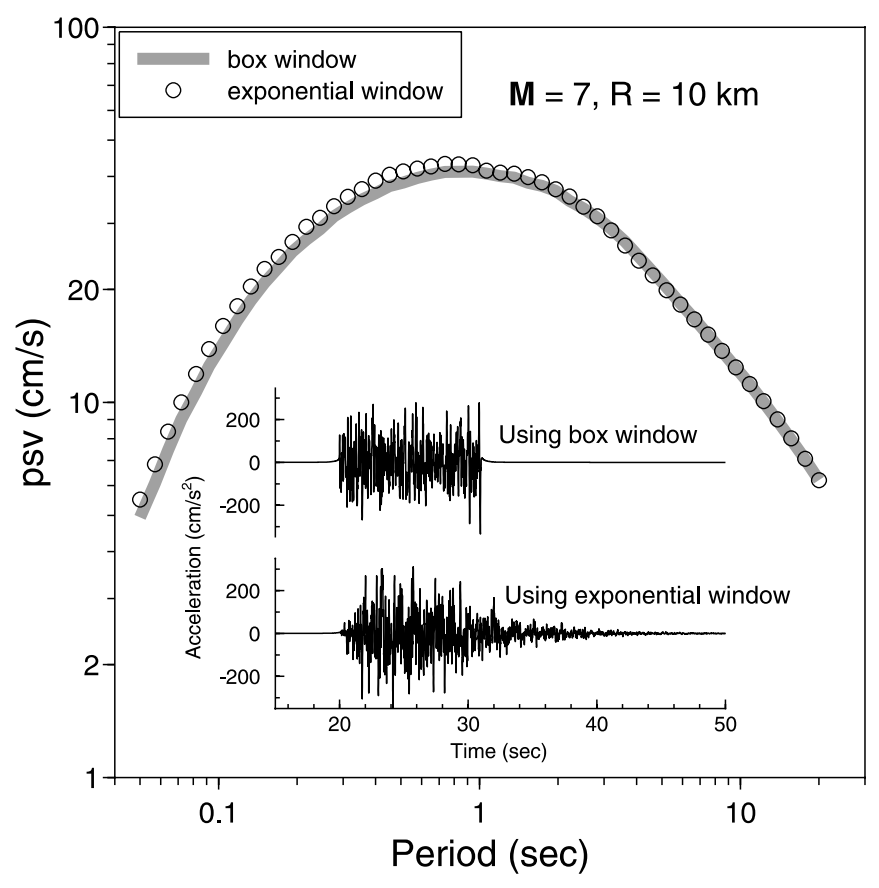

Figure 16

Comparison of waveforms and response spectra for time-domain simulations using the box and the exponential windows to shape the noise. The response spectra are averages from a suite of 640 simulations, whereas the time series are for a single realization. The simulations are for the AS00 model, as specified in

Table 2, 3, and 4 . 
In applications, it is most common to compute the ground acceleration $\left(I(f)=(2 \pi f \sqrt{-1})^{2}\right.$ in equation (1)) and then derive other measures of ground motion from the time series of ground acceleration. Figure 17 shows examples of various types of motion for magnitude 4 and 7 earthquakes; magnitude was the only thing that changed in the program input. Individual time series should be used with caution, however, for there is no guarantee that the spectrum of each realization will be close to the "target" spectrum $Y\left(M_{0}, R, f\right)$; it is only the mean of the individual spectra for a number of simulations that will match the target spectrum. An example of this is shown in Figure 18, in which the mean of the spectra from 640 realizations is almost indistinguishable from the target spectrum, although the spectrum of a randomly chosen individual realization deviates significantly from the mean at some frequencies.

It is important to note that the variability of ground-motion parameters obtained from a suite of simulations does not represent the variability observed in real groundmotion parameters. Simulating the observed variability requires running the simulations for model parameters chosen from distribution functions for those parameters (see, e.g., EPRI, 1993).

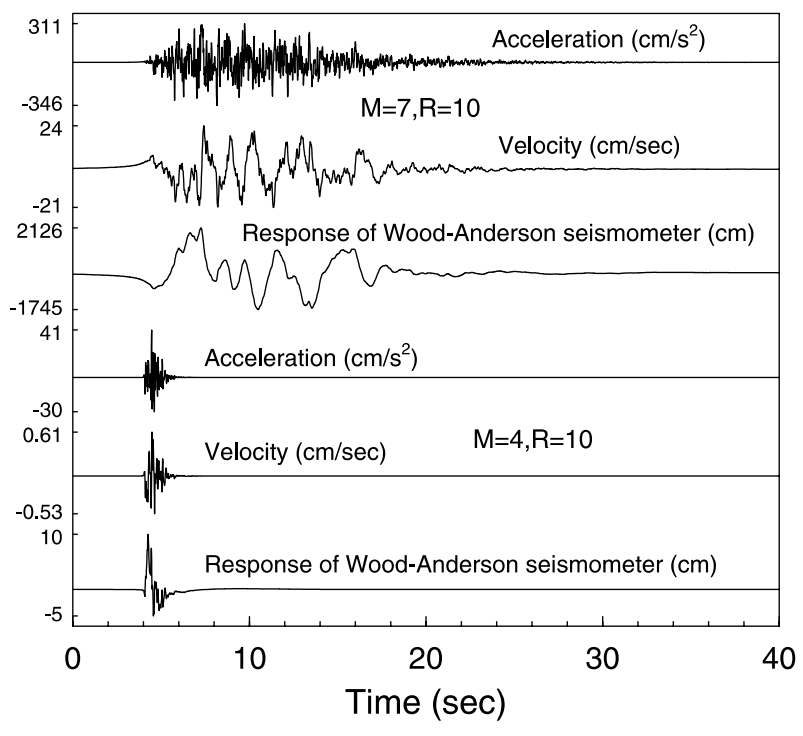

Figure 17

Time series for magnitude 4 and 7 earthquakes. The acceleration was computed using the stochastic method and the AS00 model, as specified in Tables 2, 3, and 4, and the velocity and response of a WoodAnderson seismometer were obtained from the simulated accelerations; an acausal low-cut filter with a cut-off frequency of $0.02 \mathrm{~Hz}$ was applied to the acceleration time series before the velocity and WoodAnderson response were computed. 


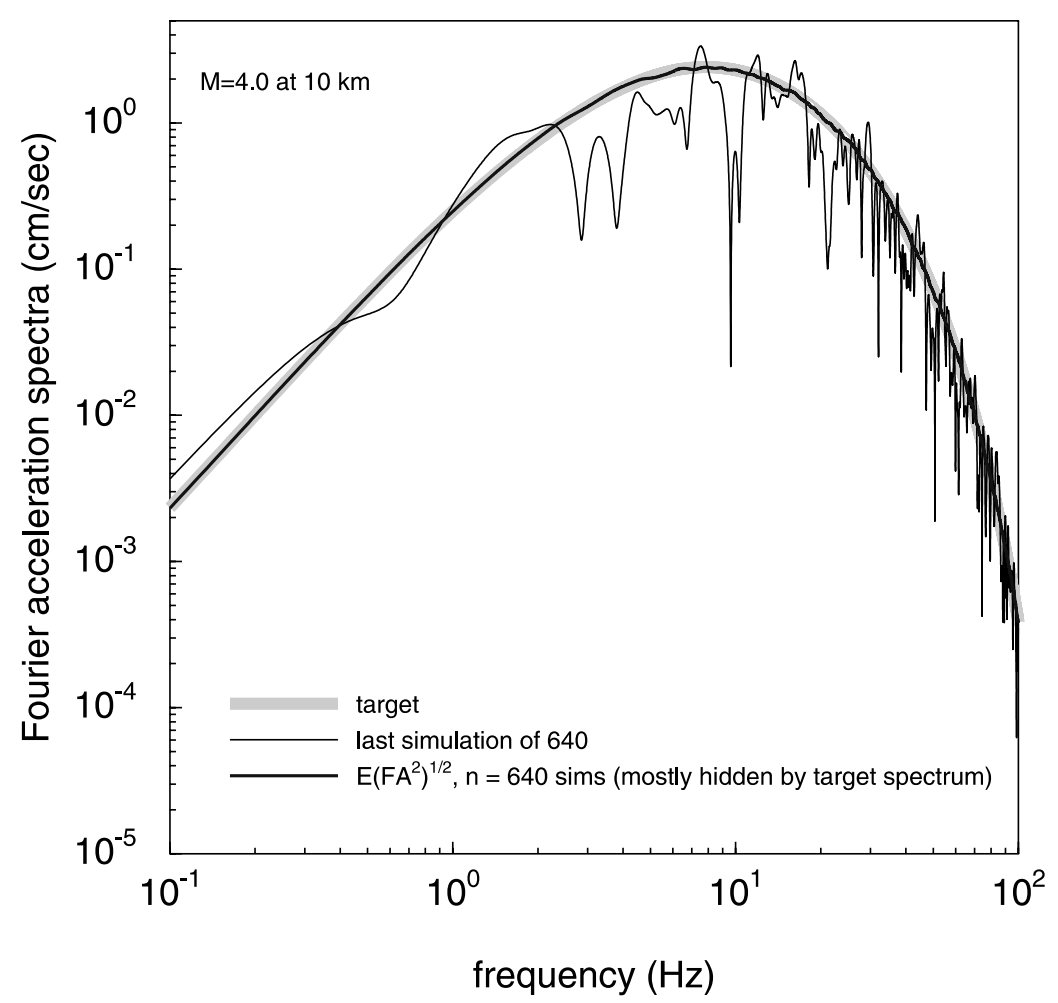

Figure 18

The model (target) spectrum, the spectrum from a single realization, and the spectrum from an average of 640 realizations. Any one realization can differ markedly from the model spectrum, but on average the simulations match the model spectrum. The simulations are for the AS00 model, as specified in Table 2, 3, and 4.

\section{Peak Motions from Random Vibration Theory}

A very rapid way of obtaining measures of peak motion (response spectra, peak acceleration, peak velocity, peak displacement, peak response of instruments for magnitude determination, Arias intensity, etc.) is to use random-vibration theory. In essence, random-vibration theory provides an estimate of the ratio of peak motion $\left(y_{\max }\right)$ to rms motion $\left(y_{\mathrm{rms}}\right)$, and Parseval's theorem is used to obtain $y_{\mathrm{rms}}$ in terms of an integral of the squared amplitude spectrum $|Y|^{2}$, where $|Y|^{2}$ contains the response of the particular measure of ground motion (e.g., equation (21) or (22)) for which peak values are desired.

The ratio of peak to rms motion is given by equations from CARTWRIGHT and Longuet-HigGins (1956), who used the analysis in Rice (1954) to develop a method for predicting extrema of ocean waves from spectral characteristics of a continuous record of sea heights. In order to use their results for the extrema of transient 
earthquake ground motions, I had to pay special attention to the definition of duration used in the equations, as described below.

After a change of variable to remove an integrable singularity, CARTWRIGHT and LONGUET-Higgins' (1956) equation (their equation (6.8)) for the ratio of peak to rms motion is

$$
\frac{y_{\mathrm{max}}}{y_{\mathrm{rms}}}=2 \int_{0}^{\infty}\left\{1-\left[1-\xi \exp \left(-z^{2}\right)\right]^{N_{e}}\right\} d z
$$

where

$$
\xi=\frac{N_{z}}{N_{e}}
$$

and $N_{z}, N_{e}$ are the number of zero crossings and extrema, respectively (extrema correspond to all places where the first derivative of the time series equals zero; for a broadband function, there can be numerous local extrema). For large $N$

$$
\frac{y_{\max }}{y_{\mathrm{rms}}}=\left[2 \ln \left(N_{z}\right)\right]^{1 / 2}+\frac{0.5772}{\left[2 \ln \left(N_{z}\right)\right]^{1 / 2}} .
$$

The integral in equation (29) is well-behaved numerically, and therefore in my applications it, rather than the asymptotic equations in equation (31), is used.

In the equations above, the number of zero crossings and extrema are related to the frequencies of zero crossings $\left(f_{z}\right)$ and extrema $\left(f_{e}\right)$ and to duration $(T)$ by the equation

$$
N_{z, e}=2 \tilde{f}_{z, e} T
$$

where the frequencies are given by

$$
\tilde{f}_{z}=\frac{1}{2 \pi}\left(m_{2} / m_{0}\right)^{1 / 2}
$$

and

$$
\tilde{f}_{e}=\frac{1}{2 \pi}\left(m_{4} / m_{2}\right)^{1 / 2}
$$

In these equations, $m_{k}, k=0,2,4$ are moments of the squared spectral amplitude. These play a fundamental role in random vibration theory and are defined for any integer $k$ as

$$
m_{k}=2 \int_{0}^{\infty}(2 \pi f)^{k}|Y(f)|^{2} d f
$$

where the spectrum $Y$ is given by equation (1) and includes the specific type of ground motions, as specified by equations (21) or (22). $y_{\mathrm{rms}}$ is simply 


$$
y_{\mathrm{rms}}=\left(m_{0} / T\right)^{1 / 2} .
$$

Being an integral of the squared acceleration, the Arias intensity is closely related to the 0 -th spectral moment:

$$
I_{x x}=\frac{\pi}{2 g} m_{0} .
$$

Seismic waves from earthquakes are inherently nonstationary, and the response of resonant systems (local site layering or mechanical oscillators) to those waves will have significant correlation between adjacent peaks. Both of these characteristics violate basic assumptions of the random vibration theory just discussed. Despite this, the theory works very well in predicting ground motions, although some simple refinements are needed for oscillator response when the oscillator period is longer than the duration of ground motion or for lightly damped oscillators, for which the response continues well past the random ground-motion excitation. Examples of these cases, computed using time-domain simulations, are shown in Figure 19. For the small earthquake, the 10 -sec oscillator response is almost equal to the ground displacement and has a short duration. On the other hand, the response of the oscillator to the larger earthquake rings on for a duration significantly in excess of the ground motion duration. The problem is in defining durations to use in determining rms and in determining the number of cycles of quasi-stationary motion to be used in the relation between $y_{\max }$ and $y_{\text {rms. }}$. BOORE and JOYNER (1984) found that good results could be obtained if two durations were used: one duration $\left(T_{\mathrm{rms}}\right)$ for the computation of the rms in equation (36), and the other, smaller, duration for the determination in equation (32) of the number of zero crossings $\left(N_{z}\right)$ or extrema $\left(N_{e}\right)$ used in evaluating $y_{\max } / y_{\mathrm{rms}}$. For the latter BOORE and JoYNER (1984) use the duration of ground motion $\left(T_{g m}\right)$, such as that shown in Figure 9. From considerations of oscillator response and numerical experiments with time-domain simulations, they proposed the following equation for the time $T_{\mathrm{rms}}$ to be used in the computation of rms:

$$
T_{\mathrm{rms}}=T_{g m}+T_{o}\left(\frac{\gamma^{n}}{\gamma^{n}+\alpha}\right),
$$

where $\gamma=T_{g m} / T_{o}$ and the oscillator duration is given by $T_{o}=1 /\left(2 \pi f_{r} \zeta\right)$. For small and large earthquakes $T_{\mathrm{rms}}$ approaches $T_{g m}$ and $T_{g m}+T_{o}$, respectively, which is consistent with the oscillator responses shown in Figure 19. The constants $n$ and $\alpha$ were determined from numerical experimentation, with values $n=3$ and $\alpha=1 / 3$. Recently, LiU and PezeshK (1999) have found somewhat better comparisons between time domain and random vibration theory results by setting $n=2$ and

$$
\alpha=\left[2 \pi\left(1-\frac{m_{1}^{2}}{m_{0} m_{2}}\right)\right]^{1 / 2},
$$




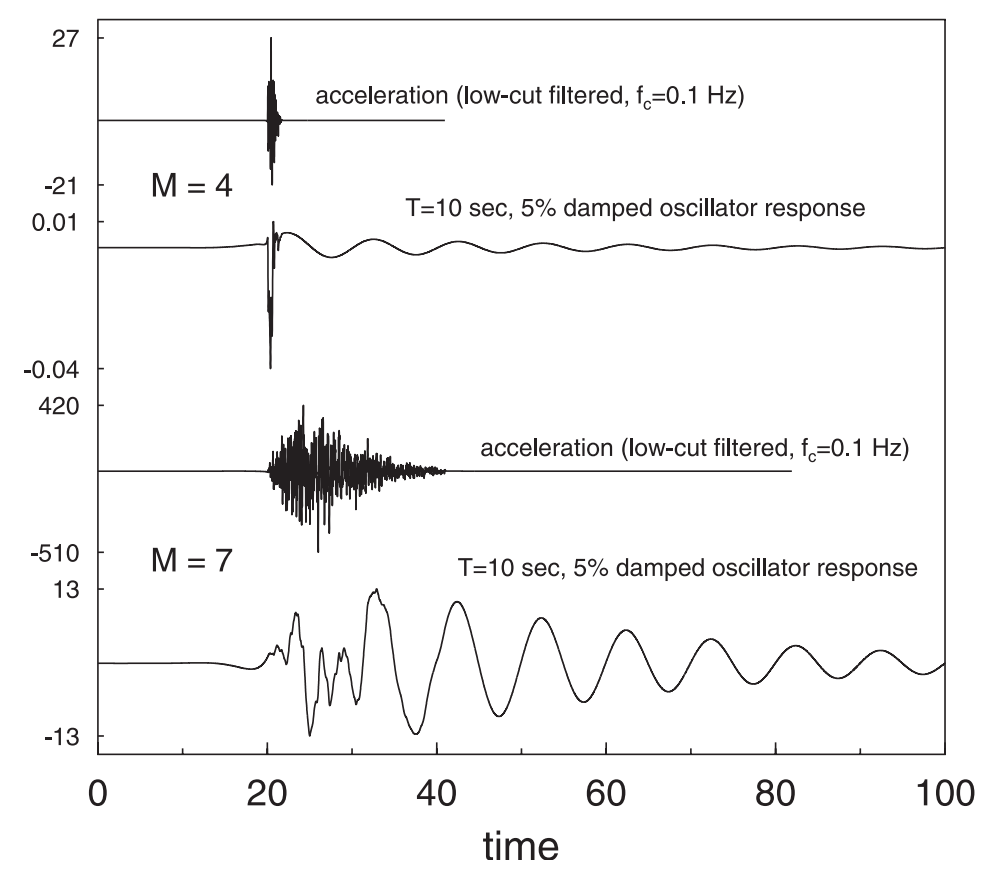

Figure 19

Simulated acceleration time series and computed response of 10.0-sec, 5-percent-damped oscillator for magnitude 4 and 7 earthquakes at $10 \mathrm{~km}$. Because the relative shape is important, each trace has been scaled individually (the actual amplitudes are given to the left of the y-axis-acceleration in $\mathrm{cm} / \mathrm{s}^{2}$ and oscillator response in $\mathrm{cm}$ ), The simulations are for the AS00 model, as specified in Table 2, 3, and 4. The accelerations differ from those in Figure 17 because the seeds used in generating the random numbers needed in the simultations were not the same.

where $m_{i}, i=0,1,2$ are given by equation (35). According to Liu and Pezeshk, equation (39) accounts for the bandwidth of the ground motion. Comparisons of response spectra computed using time-domain calculations (for 10, 40, 160, and 640 simulations) and random-vibration calculations with both the Boore-Joyner and the Liu-Pezeshk oscillator corrections are shown in Figures 20 and 21. The figures show good agreement between the time-domain and the random-vibration theory calculations, with the Liu-Pezeshk correction giving somewhat better answers for $\mathbf{M} 7$ earthquake at periods between 5 and about 12 secs (Fig. 21). The comparisons between the different ways of doing the oscillator correction, however, is model- and period-dependent. For example, the comparison in Liu and Pezeshk's paper indicates that their correction is significantly better than the Boore-Joyner correction for small earthquakes, which is a different conclusion than obtained from the comparisons shown in Figure 20. Figures 20 and 21 also indicate that more than 40 simulations may be required adequately capture the mean of the ground motions. 


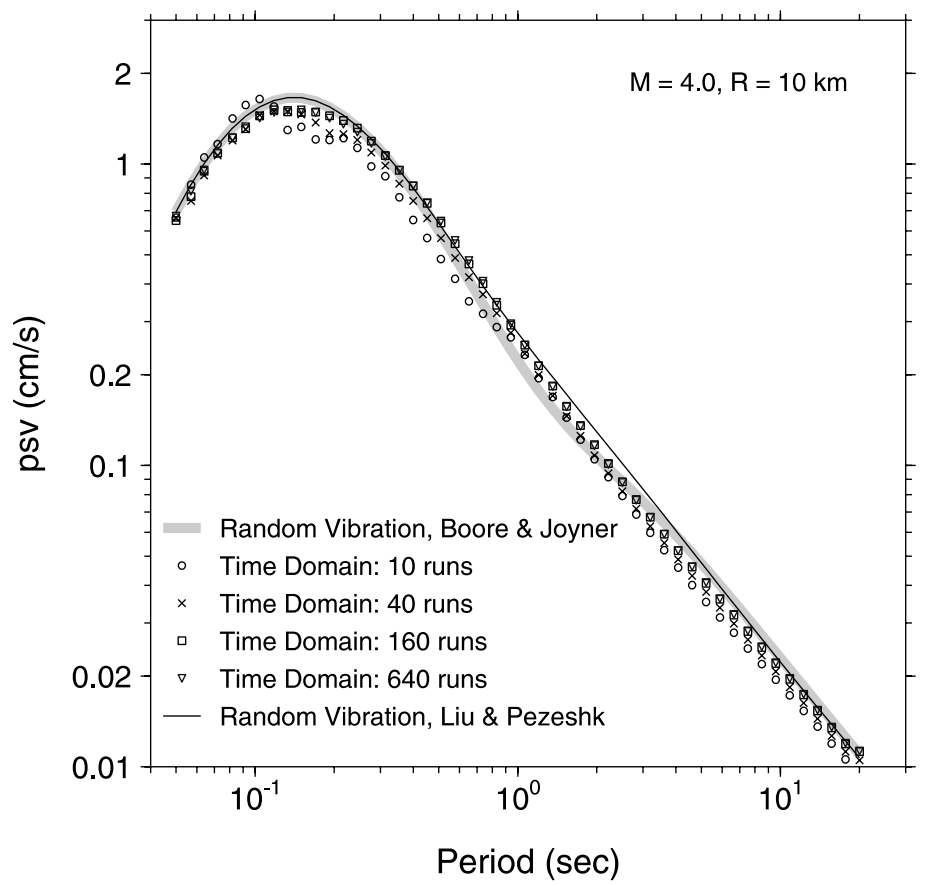

Figure 20

Comparison of simulations using the time-domain calculations with various values of the number of simulations, with a different seed for the random-number generator for each set of simulations. The random-vibration results are shown for comparison, using both the BOORE and JOYNER (1984) and LIU and PEzeshK (1999) modification of random-vibration theory for oscillator response. The calculations are for magnitude 4 at $10 \mathrm{~km}$. The simulations are for the AS00 model, as specified in Table 2, 3, and 4.

\section{Applications}

The stochastic method has been widely applied, but rather than attempt to discuss a number of specific applications, I have included in Table 5 a fairly comprehensive list of applications, separated by primary geographic region. There are many ways in which the stochastic method has been used, and the effectiveness of the method has been demonstrated by fitting observations ranging from negativemagnitude rockbursts to great earthquakes at teleseismic distances. Calibrations of the method, which may involve finding the parameters so as to fit empirically-derived equations for predicting ground motions, and validations of the method, which consist of checking predictions against data (but not the same data used in deriving the necessary parameters) are included in a number of the references. The method can be used in absolute or relative senses. For example, predicting ground-shaking going from the source to the site is an absolute prediction, whereas predicting the ratio of ground-shaking for two source models is a relative prediction. Examples of both of these uses are given in Figure 22-an admittedly complicated figure, but one 


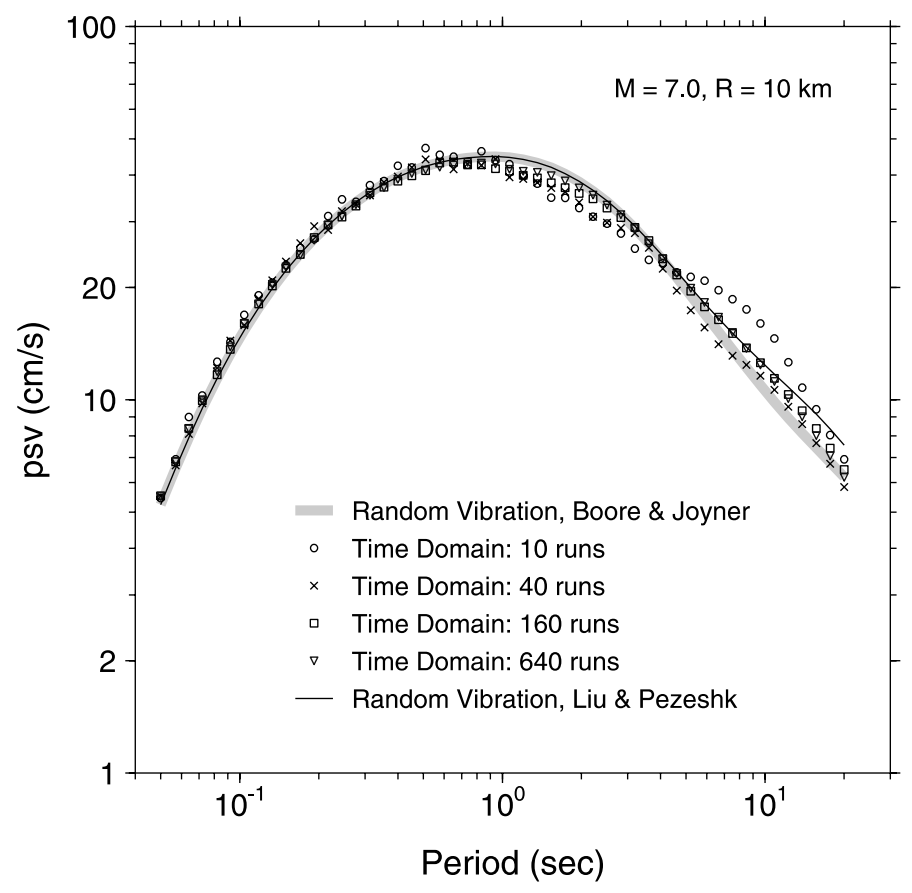

Figure 21

Comparison of simulations using the time-domain calculations with various values of the number of simulations, with a different seed for the random-number generator for each set of simulations. The random-vibration results are shown for comparison, using both the BOORE and JOYNER (1984) and LiU and Pezesho (1999) modification of random-vibration theory for oscillator response. The calculations are for magnitude 7 at $10 \mathrm{~km}$. The simulations are for the AS00 model, as specified in Table 2, 3, and 4 .

which makes a number of points; see BOORE (1999) for details. In Figure 22 the circles are absolute predictions of response spectra for magnitude 5.6 and 7.6 earthquakes using the stochastic method. For comparison, the dashed lines are response spectra from empirical analyses of data, and the heavy solid line for $\mathbf{M}=5.6$ is the observed spectrum for a recording of the 1990 Upland, California, earthquake; the light solid line is the response spectrum computed for just the $S$-wave portion of the record, and excludes the longer-period surface waves. The absolute predictions for $\mathbf{M}=5.6$ are in reasonable agreement with the observations for shorter periods and for longer periods when the surface waves are excluded; the mismatch for longer-period response spectra obtained from the whole record is due to the lack of the surface waves in the stochastic method, which is a limitation of the method as usually applied. The heavy solid line for $\mathbf{M}=7.5$ is based on the observed spectrum of the smaller earthquake, corrected by the relative difference of motions for magnitude 7.5 and 5.6 earthquakes, as predicted by the stochastic method. The relative prediction of ground motions has also been used by CAMPBELL (1999) in the hybrid prediction of ground motions in eastern North America, in which he uses 
Table 5

Some references for applications of the stochastic method

Western North America

Anderson and Lei (1994), AtKinson (1995, 1997), AtKinson and Boore (1997b), AtKinson and Cassidy (2000), Atkinson and Silva (1997, 2000), Aviles and Perez-Rocha (1998), Ben-Zion and Zhu (2002), Beresnev (2002), Beresnev and AtKinson (1998b), Boore (1986a, 1995, 1999), Boore and JoYNer (1997), Boore et al. (1992), CHIN and AKI (1991, 1996), HANKS and BoORE (1984), HARTZell et al. (1999, 2002), Iglesias et al. (2002), Luco (1985), Mahdyiar (2002), McGuire and Hanks (1980), McGuire et al. (1984), Papageorgiou and Aki (1983b), Schneider and Silva (2000), Schneider et al. (1993), Silva and Wong (1992), Silva et al. (1991), Singh et al. (1989), Vetter et al. (1996),

WenNerberg (1996), Wong and Silva (1990, 1993, 1994), Wong et al. (1993), Youngs and Silva (1992)

Central and Eastern North America

AtKinson (1984, 1989, 1990), AtKinson and Beresnev (1998, 2002), AtKinson and Boore (1987, 1990, 1995, 1997a, 1998), AtKinson and Hanks (1995), AtKinson and Somerville (1994), Beresnev and AtKinson (1999), Bollinger et al. (1993), Boore (1989a), Boore and AtKinson (1987), Boore and Joyner (1991), CAmpbell (2002), Chapman et al. (1990), EPRI (1993), FranKel et al. (1996), Greig and AtKinson (1993), Hanks and Johnston (1992), Harik et al. (1997), Herrmann and AKInCi (2000), Hwang (2001), Hwang and Huo (1994, 1997), Hwang et al. (1997, 2001a, 2001b), Kumar (2000), Silva et al. (1989), Toro (1985), Toro and MCGuire (1987), Toro et al. (1988, 1992, 1997), Wen and Wu (2001)

Other Parts of the World or Several Regions Combined

Akinci et al. (2001), ASCE (2000), AtKinson and Greig (1994), Berardi et al. (1999), Beresnev and Atrinson (2002), Boore (1986b), Castro et al. (2001), Chen and AtKinson (2002), Chernov and Sokolov (1999), De Natale et al. (1988), Faccioli (1986), Hartzell and Heaton (1988), Harmsen (2002), Hlatywayo (1997), Malagnini and Herrmann (2000), Malagnini et al. (2000), Margaris and Boore (1998), Margaris and Hatzidimitriou (2002), Margaris and Papazachos (1999), McGuire (1984), Ólafsson et al. (1998), Miyake et al. (2001), Pitarka et al. (2000, 2002), Roumelioti and Kiratzi (2002), Rovelli et al. (1988, 1991, 1994a, 1994b), SATOH (2002), SATOH et al. (1997), Scherbaum (1994), Scherbaum et al. (1994), Silva (1997), Silva and Costantino (1999), Silva and Darragh (1995), Silva and Green (1989), Silva et al. (2000a, 2000b, 2002), Singh et al. (1999, 2002), SoKolov (1997, 1998, 2000a, 2000b), Sokolov et al. (2000, 2001), SuZuKi et al. (1998), Tremblay and AtKinson (2001), Tsai (1997, 1998a, 1998b), Wong et al. (1991)

the stochastic method to modify empirically derived western U.S. ground motions for differences in source, propagation, and site.

Other general areas in which the stochastic method has been applied include:

- Generate suites of ground motions for many magnitudes and distance, and use these to derive ground-motion prediction equations and tables of motion. This is the basis for the CEUS motions used in the U.S. National Hazard Maps.

- Use as a basis for design-motion specification of critical structures.

- Find parameters controlling spectral content (e.g., $\Delta \sigma, \kappa)$.

- Use in parameter sensitivity studies.

- Relate time-domain measures of ground motion to frequency-domain descriptions.

- Generate time series for use in nonlinear analyses (structural, site response, landslides, liquefaction).

- Use to compute subfault motions in simulations of extended ruptures.

One topic I have not discussed is that of uncertainties in the predictions; this has been a major focus of a study by EPRI (1993) (see also Silva, 1992; Toro et al., 


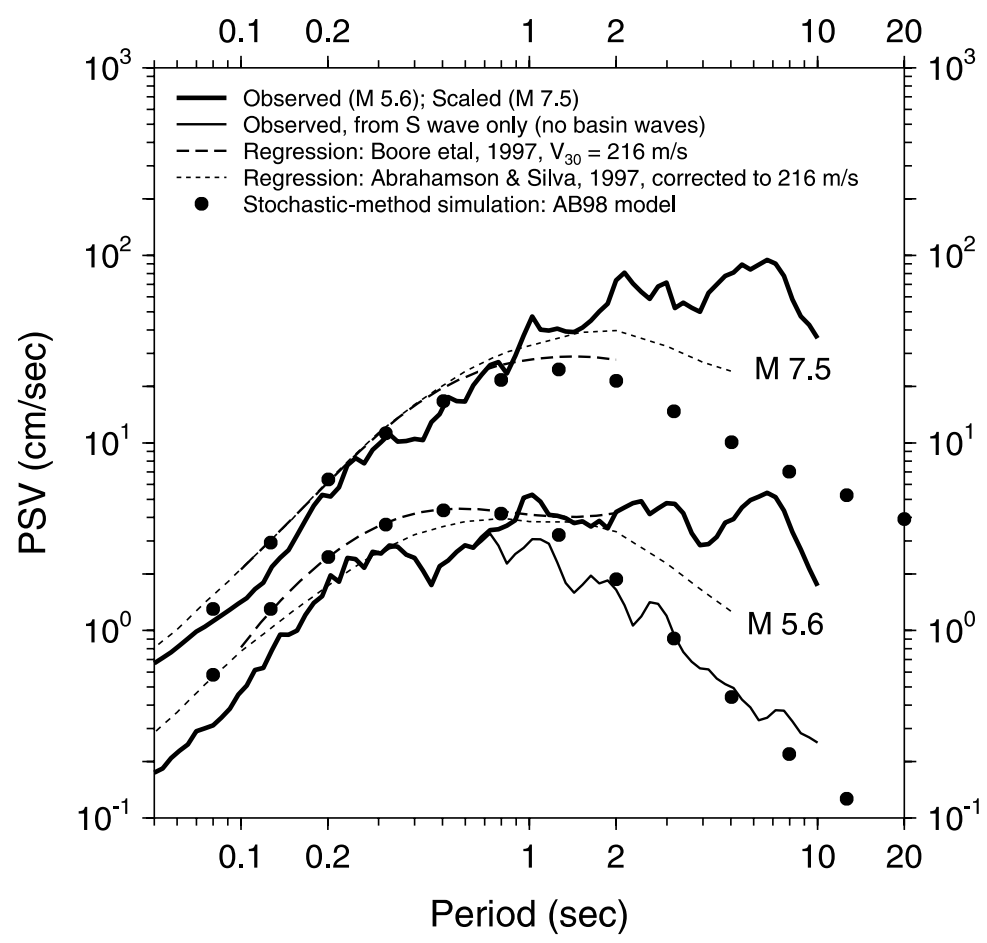

Figure 22

5\%-damped, pseudo-velocity response spectra $(P S V)$ for a small earthquake $(\mathbf{M}=5.6)$ and a large earthquake (M=7.5) (heavy solid lines). The $P S V$ for the large event has been derived from the small event assuming ATKINSON and Boore (1998) (AB98) source models. Also shown are the predictions from two regression analyses (dashed lines) and from stochastic-method simulations (solid circles). The light solid line for the $\mathbf{M}=5.6$ event was computed from the $S$-wave portion of the event (the first 35 sec of the recorded motion). (Modified from Boore, 1999.)

1997). An example of this uncertainty was shown in Figure 3, which displays the range of Fourier spectra for predictions of ground motions in eastern North America (the variations in predicted ground motions are similar to the variations in Fourier spectra). AtKinson and BoORE (1998) showed that the ATKINSON and BoORE (1995) model best fits response spectra computed from earthquake records in eastern North America and from other tectonically comparable areas. More than half of the events providing data used in the comparisons, however, had magnitudes less than or equal to 5. For this reason uncertainty exists in how applicable any one of the proposed source models would be in predicting ground motions from earthquakes in eastern North America large enough to constitute significant seismic hazard. A sensible way of dealing with this uncertainty is to base hazard calculations on a weighted average of ground motions from a number of the proposed source models (but all calculations still employ the stochastic-method simulations). The choice of weights then becomes the issue; this topic has been dealt with for eastern North America by 
expert elicitations (SAVY et al., 1998) using the concepts discussed in BudNitz et al. (1997, 1998) and for the development of the National Hazard Maps by informed subjective opinion, based on a series of regional workshops (e.g., Frankel et al., 1996 (currently being updated — see http://geohazards.cr.usgs.gov/eq/)).

\section{Limitations and Improvements}

Comparisons of stochastic-method predictions with empirically-determined ground motions indicates that the stochastic method is useful for simulating mean ground motions expected for a suite of earthquakes having a specified magnitude and fault-station distance. Care must be used, however, when the method is used to simulate site-specific and earthquake-specific ground motions. As described in this paper, the method does not include any phase effects due to the propagating rupture and to the wave propagation enroute to the site (including local site response). In addition, the differences between the various components of motion and different wave types are ignored. For these reasons, fault-normal effects, phase differences over horizontal distances, spatial correlations, directivity, etc. are not captured by the simulated motions. It should be possible to include some of these effects in the method, and I am aware of some efforts along these lines (e.g., LoH, 1985; LoH and YeH, 1988; TAMURA et al., 1991; TAMURA and Aizawa, 1992).

As noted before (Figure 18), the Fourier spectrum of each time series realization may diverge from the "target" Fourier spectrum $Y\left(M_{0}, R, f\right)$. For this reason, when the method is used to simulate a suite of time series for use in engineering design, it is important to check the Fourier or response spectrum of each simulation to be sure that it does not deviate too far from the desired spectrum. In practice, this will mean choosing the best subset from a number of simulations. This approach has been used by WEN and WU (2001) and by HARMSEN (2002), both of whom used the similarity to a specified response spectrum as the basis for choosing the time series (but the two papers used different "goodness-of-fit" criteria).

The method also assumes stationarity of the frequency content with time. As the example in Figure 22 shows, this is a poor assumption for situations, such as deep sedimentary basins (e.g., JOYNER, 2000), where long-period surface waves occur. It should be possible to incorporate these waves into the method.

The duration in applications of the method is independent of frequency. RAOOF et al. (1999), however, find that duration is frequency-dependent. Modifications of the method to account for frequency-dependent duration would be relatively easy for time-domain simulations (simulating the motions for a series of narrow-band filters), but might be more difficult for simulations of motions using random-vibration theory.

An apparent limitation often expressed is that most of the models based on the stochastic method are fundamentally point-source models. This may not be as 
important a limitation as might at first be thought. Although it is true that nearand intermediate-field terms are lacking, in most applications the frequencies are high enough that the far-field terms dominate, even if the site is near the fault. Furthermore, the effects of a finite-fault averaged over a number of sites distributed around the fault (to average over radiation pattern and directivity effects) can be captured in several ways: 1) using the closest distance to faulting (as is done in empirically derived ground-motion prediction equations) as the source-to-site distance; 2) using a two-corner source spectrum (ATKINSON and SILVA, 2000); 3) allowing the geometrical spreading to be magnitude dependent (Silva et al., 2002). In addition, it should be possible to extend the method to account for specific fault-station geometries in a simple way, perhaps combining the simple computation of envelopes of acceleration (MIDORIKAWA and Kobayashi, 1978; COCCO and BoATwright, 1993) with statistical descriptions of the source (e.g., Lomnitz-Adler and Lund, 1992; Herrero and BernARd, 1994; JOYNER, 1995; BERNARD et al., 1996; HiSADA, 2000). The overriding philosophy of such an effort would be to capture the essence of motions from an extended rupture without sacrificing the conceptual simplicity of the stochastic method.

\section{Conclusions}

The stochastic method is a simple, yet powerful, means for simulating ground motions. It is particularly useful for obtaining ground motions at frequencies of interest to earthquake engineers, and it has been widely applied in this context.

My source codes, written in FORTRAN, and executables that can be used on a PC can be obtained from my web site (http://quake.usgs.gov/ boore) or via anonymous ftp on samoa.wr.usgs.gov in directory get. Programs are included both for time-domain and for random-vibration simulations. The user should download the files README.TXT, SMSIMxxx.ZIP, SITEAxxx.ZIP, and SMSIM_MANUAL.PDF where " $\mathrm{xxx}$ " is the current version number, and follow the instructions in README.TXT to extract and to use the programs. SMSIM_MANUAL.PDF contains the manual for the program (BOORE, 2000). The manual is also available online at http://geopubs.wr.usgs.gov/open-file/of00-509/.

\section{Acknowledgments}

I wish to thank Bob Herrmann for the record section shown in Figure 4, Gail Atkinson for sending various data files, and Nancy Blair for help in finding papers that have used the stochastic method. In addition, the comments John Anderson, Tom Hanks, Bob Herrmann, Bill Joyner, Chuck Mueller, and Walt Silva were very helpful. 
Most importantly, I want to thank Keiiti Aki for the guidance and inspiration that started me on my career path over 30 years ago.

\section{REFERENCES}

Abrahamson, N. A. and Silva, W. J. (1997), Empirical Response Spectral Attenuation Relations for Shallow Crustal Earthquakes, Seism. Res. Lett. 68, 94-127.

AKI, K. (1966), Generation and Propagation of G Waves from the Niigata Earthquake of June 16, 1964. Part 2. Estimation of Earthquake Moment, Released Energy, and Stress-strain Drop from the G-Wave Spectrum, Bull. Earthq. Res. Inst. 44, 73-88.

AKI, K. (1967), Scaling Law of Seismic Spectrum, J. Geophys. Res. 72, 1217-1231.

AкI, K. (1980), Attenuation of Shear-waves in the Lithosphere for Frequencies from 0.05 to $25 \mathrm{~Hz}$, Phys. Earth Planet. Inter. 21, 50-60.

Akinci, A., Malagnini L., Herrmann R. B., Pino N. A., Scognamiglio L., and Eyidogan, H. (2001), High-frequency ground motion in the Erzincan region, Turkey: Inferences from small earthquakes, Bull. Seism. Soc. Am. 91, 1446-1455

Anderson, J. G. and Hough, S. E. (1984), A Model for the Shape of the Fourier Amplitude Spectrum of Acceleration at High Frequencies, Bull. Seismol. Soc. Am. 74, 1969-1993.

Anderson, J. G. and Lei, Y. (1994), Nonparametric Description of Peak Acceleration as a Function of Magnitude, Distance, and Site in Guerero, Mexico, Bull. Seismol. Soc. Am. 84, 1003-1017.

Arias, A. A Measure of Earthquake Intensity. In Seismic Design for Nuclear Power Plants (Robert J. Hansen, ed.) (The M.I.T. Press, Cambridge, Mass. 1970) pp. 438-483.

ASCE (2000), Seismic Analysis of Safety-Related Nuclear Structures, American Society of Civil Engineers, ASCE-98.

Atkinson, G. M. (1984), Attenuation of Strong Ground Motion in Canada from a Random Vibrations Approach, Bull. Seismol. Soc. Am. 74, 2629-2653.

AtKinson, G. M. (1989), Implications of Eastern Ground-Motion Characteristics for Seismic Hazard Assessment in Eastern North America. In Earthquake Hazards and the Design of Constructed Facilities in the Eastern United States (K. H. Jacob and C. J. Turkstra, eds.) Annals of the New York Academy of Sciences 558, 128-135.

Atkinson, G. M. (1990), A Comparison of Eastern North American Ground Motion Observations with Theoretical Predictions, Seism. Res. Lett. 61, 171-180.

Atkinson, G. M. (1993a), Notes on Ground Motion Parameters for Eastern North America: Duration and H/V Ratio, Bull. Seismol. Soc. Am. 83, 587-596.

Atkinson, G. M. (1993b), Earthquake Source Spectra in Eastern North America, Bull. Seismol. Soc. Am. $83,1778-1798$.

Atkinson, G. M. (1995), Attenuation and Source Parameters of Earthquakes in the Cascadia Region, Bull. Seismol. Soc. Am. 85, 1327-1342.

AtKinson, G. M. (1996), The High-frequency Shape of the Source Spectrum for Earthquakes in Eastern and Western Canada, Bull. Seismol. Soc. Am. 86, 106-112.

Atkinson, G. M. (1997), Empirical Ground Motion Relations for Earthquakes in the Cascadia Region, Canadian J. Civil Eng. 24, 64-77.

Atkinson, G. M. and Beresnev, I. A. (1998), Compatible Ground-motion Time Histories for New National Seismic Hazard Maps, Canadian J. Civil Eng. 25, 305-318.

Atkinson, G. M. and Beresnev, I. A. (2002), Ground motions at Memphis and St. Louis from M 7.5-8.0 earthquakes in the New Madrid seismic zone, Bull Seism. Soc. Am. 92, 1015-1024.

Atkinson, G. M. and Boore, D. M. (1987), On the $m_{N}$, M Relation for Eastern North American Earthquakes, Seism. Res. Lett. 58, 119-124.

Atkinson, G. M. and Boore, D. M. (1990), Recent Trends in Ground Motion and Spectral Response Relations for North America, Earthquake Spectra 6, 15-35.

Atkinson, G. M. and Boore, D. M. (1995), Ground Motion Relations for Eastern North America, Bull. Seismol. Soc. Am. 85, 17-30. 
Atkinson, G. M. and Boore, D. M. (1997a), Some Comparisons between Recent Ground-motion Relations, Seism. Res. Lett. 68, 24-40.

Atkinson, G. M. and Boore, D. M. (1997b), Stochastic Point-source Modeling of Ground Motions in the Cascadia Region, Seism. Res. Lett. 68, 74-85.

AtKinson, G. M. and Boore, D. M. (1998), Evaluation of Models for Earthquake Source Spectra in Eastern North America, Bull. Seismol. Soc. Am. 88, 917-934.

AtKinson, G. M. and CAssidy J. F. (2000), Integrated use of seismograph and strong-motion data to determine soil amplification: Response of the Fraser River Delta to the Duvall and Geoprgia Strait earthquakes, Bull. Seism. Soc. Am. 90, 1028-1040.

Atkinson, G., and Greig, G. (1994), On the relationship between linear and nonlinear response parameters. Proc. Fifth U.S. National Conference on Earthquake Engineering, Chicago, July 10-14, 1994, 4, 561-570.

Atkinson, G. M. and Hanks, T. C. (1995), A High-frequency Magnitude Scale, Bull. Seismol. Soc. Am. $85,825-833$.

Atkinson, G. M. and Mereu, R. F. (1992), The Shape of Ground Motion Attenuation Curves in Southeastern Canada, Bull. Seismol. Soc. Am. 82, 2014-2031.

Atkinson, G. M. and Silva, W. (1997), An Empirical Study of Earthquake Source Spectra for California Earthquakes, Bull. Seismol. Soc. Am. 87, 97-113.

Atrinson, G. M. and Silva, W. (2000), Stochastic Modeling of California Ground Motions, Bull. Seismol. Soc. Am. 90, 255-274.

Atkinson, G. M. and Somerville, P. G. (1994), Calibration of Time History Simulation Methods, Bull. Seismol. Soc. Am. 84, 400-414.

Aviles, J. and Perez-Rocha, L. E. (1998), Site Effects and Soil-structure Interaction in the Valley of Mexico, Soil Dyn. Earthq. Eng. 17, 29-39.

Ben-Zion, Y. and Zhu, L. (2002), Potency-magnitude scaling relations for southern California earthquakes with $1.0<M_{L}<7.0$, Geophys. J. Int. 148, F1-F5.

Berardi, R., Jimenez, M., Zonno, G., and Garcia-Fernandez, M. (1999), Calibration of Stochastic Ground Motion Simulations for the 1997 Umbria-Marche, Central Italy, Earthquake Sequence. Proc. 9th Intl. Conf. On Soil Dynamics and Earthquake Engineering, SDEE 99, Aug. 1999, Bergen, Norway.

BERESNEV, I.A. (2002). Nonlinearity at California generic soil sites from modeling recent strong-motion data, Bull. Seism. Soc. Am. 92, 863-870

Beresnev, I. A. and Atkinson, G. M. (1997), Modeling Finite-fault Radiation from the $\omega^{n}$ Spectrum, Bull. Seismol. Soc. Am. 87, 67-84.

Beresnev, I. A. and AtKinson, G. M. (1998a), FINSIM-a FORTRAN Program for Simulating Stochastic Acceleration Time Histories from Finite Faults, Seism. Res. Lett. 69, $27-32$.

Beresnev, I. A. and AtKinson, G. M. (1998b), Stochastic Finite-fault Modeling of Ground Motions from the 1994 Northridge, California Earthquake. I. Validation on Rock Sites, Bull. Seismol. Soc. Am. 88, $1392-1401$.

Beresnev, I. A. and AtKinson, G. M. (1999), Generic Finite-fault Model for Ground-motion Prediction in Eastern North America, Bull. Seismol. Soc. Am. 89, 608-625.

Beresnev, I. A. and AtKinson, G. M. (2002), Source parameters of earthquakes in eastern and western North America based on finite-fault modeling, Bull. Seism. Soc. Am. 92, 695-710.

Bernard, P., Herrero, A., and Berge, C. (1996), Modeling Directivity of Heterogeneous Earthquake Ruptures, Bull. Seismol. Soc. Am. 86, 1149-1160.

Bontwright, J. and Choy, G. (1992), Acceleration Source Spectra Anticipated for Large Earthquakes in Northeastern North America, Bull. Seismol. Soc. Am. 82, 660-682.

Bollinger, G. A., Chapman, M. C., and Sibol, M. S. (1993), A Comparison of Earthquake Damage Areas as a Function of Magnitude across the United States, Bull. Seismol. Soc. Am. 83, 1064-1080.

Boore, D. M. (1983), Stochastic Simulation of High-frequency Ground Motions Based on Seismological Models of the Radiated Spectra, Bull. Seismol. Soc. Am. 73, 1865-1894.

Boore, D. M. (1984), Use of Seismoscope Records to Determine $M_{L}$ and Peak Velocities, Bull. Seismol. Soc. Am. 74, 315-324.

Boore, D. M. (1986a), The Effect of Finite Bandwidth on Seismic Scaling Rrelationships. In Earthquake Source Mechanics (S. Das, J. Boatwright, and C. Scholz, eds.) Geophysical Monograph 37 (American Geophysical Union, Washington, D. C. 1986a) pp. 275-283. 
Boore, D. M. (1986b), Short-period P-and S-wave Radiation from Large Earthquakes: Implications for Spectral Scaling Relations, Bull. Seismol. Soc. Am. 76, 43-64.

Boore, D. M. (1989a), Quantitative Ground-Motion Estimates. In Earthquake Hazards and the Design of Constructed Facilities in the Eastern United States (K. H. Jacob and C. J. Turkstra, eds.) Annals of the New York Academy of Sciences 558, 81-94.

Boore, D. M. (1989b), The Richter Scale: Its Development and Use for Determining Earthquake Source Parameters, Tectonophysics 166, 1-14.

Boore, D. M. (1995), Prediction of Response Spectra for the Saguenay earthquake. In Proceedings: Modeling Earthquake Ground Motion at Close Distances, Electric Power Research Institute Report EPRI TR-104975, 6-1-6-14.

Boore, D. M. (1996), SMSIM - Fortran Programs for Simulating Ground Motions from Earthquakes: Version 1.0, U.S. Geol. Surv. Open-File Rept. 96-80-A, 96-80-B, 73 pp.

Boore, D. M. (1999), Basin Waves on a Seafloor Recording of the 1990 Upland, California, Earthquake: Implications for Ground Motions from a Larger Earthquake, Bull. Seismol. Soc. Am. 89, 317-324.

Boore, D. M. (2000), SMSIM - Fortran Programs for Simulating Ground Motions from Earthquakes: Version 2.0-A Revision of OFR 96-80-A, U.S. Geol. Surv. Open-File Rept. OF 00-509, 55 pp. (available at http://geopubs.wr.usgs.gov/open-file/of00-509/).

Boore, D. M. (2002), SMSIM: Stochastic Method SIMulation of Ground Motion from Earthquakes. In IASPEI Centennial International Handbook of Earthquake and Engineering Seismology (W. Lee, K. Kanamori, P. Jennings, and C. Kisslinger, eds), Academic press, Chapter 85.13, (in press).

Boore, D. M. and AtKinson, G. M. (1987), Stochastic Prediction of Ground Motion and Spectral Response Parameters at Hard-rock Sites in Eastern North America, Bull. Seismol. Soc. Am. 77, 440-467.

Boore, D. M. and Bontwright, J. (1984), Average Body-wave Radiation Coefficients, Bull. Seismol. Soc. Am. 74, 1615-1621.

Boore, D. M. and Joyner, W. B. (1984), A Note on the Use of Random Vibration Theory to Predict Peak Amplitudes of Transient Signals, Bull. Seismol. Soc. Am. 74, 2035-2039.

Boore, D. M. and Joyner, W. B. (1991), Estimation of Ground Motion at Deep-soil Sites in Eastern North America, Bull. Seismol. Soc. Am. 81, 2167-2185.

Boore, D. M. and Joyner, W. B. (1997), Site amplifications for Generic Rock Sites, Bull. Seismol. Soc. Am. 87, 327-341.

Boore, D. M., Joyner, W. B., and Wennerberg, L. (1992), Fitting the Stochastic $\omega^{-2}$ Source Model to Observed Response Spectra in Western North America: Trade-offs between $\Delta \sigma$ and $\kappa$, Bull. Seismol. Soc. Am. 82, 1956-1963.

Boore, D. M., Joyner, W. B., and Fumal, T. E. (1997), Equations for Estimating Horizontal Response Spectra and Peak Acceleration from Western North American Earthquakes: A Summary of Recent Work, Seism. Res. Lett. 68, 128-153.

BRUne, J. N. (1970), Tectonic Stress and the Spectra of Seismic Shear Waves from Earthquakes, J. Geophys. Res. 75, 4997-5009.

Brune, J. N. (1971), Correction, J. geophys. Res. 76, 5002.

Budnitz, R. J., Apostolakis, G., Boore, D. M., Cluff, L. S., Coppersmith, K. J., Cornell, C. A., and Morris, P. A. (1997), Recommendations for Probabilistic Seismic Hazard Analysis: Guidance on Uncertainty and Use of Experts, NUREG/CR-6372, Washington, D.C.: U.S. Nuclear Regulatory Commission.

Budnitz, R. J., Apostolakis, G., Boore, D. M., Cluff, L. S., Coppersmith, K. J., Cornell, C. A., and Morris, P. A. (1998), Use of Technical Expert Panels: Applications to Probabilistic Seismic Hazard Analysis, Risk Analysis 18, 463-469.

Campbell, K. W. (1999), Hybrid Empirical Model for Estimating Strong Ground Motion in Regions of Limited Strong-motion Recordings, presented at OECD-NEA Workshop on Engineering Characterization of Seismic Input, Brookhaven National Laboratory, Upton, NY, Nov. 15-17, 1999.

Campbell, K. W. (2002), Strong Motion Attenuation Relations: Commentary and Discussion of Selected Relations. In IASPEI Centennial International Handbook of Earthquake and Engineering Seismology (W. Lee, K. Kanamori, P. Jennings, and C. Kisslinger, eds.), Academic press, Chapter 60, (in press).

CAmpbell, K. W. (2002), Prediction of strong ground motion using the hybrid empirical method: Example application to eastern North America, Bull. Seism. Soc. Am. 92 (in press). 
Cartwright, D. E. and Longuet-Higgins, M. S. (1956), The Statistical Distribution of the Maxima of a Random Function, Proc. R. Soc. London 237, 212-232.

Castro, R. R., Rovelli, A., Cocco, M., Di Bona, M., and Pacor, F. (2001), Stochastic simulation of strong-motion records from the 26 September 1997 (MW6), Umbria-Marche (central Italy) earthquake, Bull. Seism. Soc. Am. 91, 27-39.

Chapman, M. C., Bollinger, G. A., Sibol, M. S., and Stephenson, D. E. (1990), The Influence of the Coastal Plain Sedimentary Wedge on Strong Ground Motions from the 1886 Charleston, South Carolina, Earthquake, Earthquake Spectra 6, 617-640.

Chen, S.-Z. and Atkinson, G. M. (2002), Global comparisons of earthquake source spectra, Bull. Seism. Soc. Am. 92, 885-895.

Chernov, Y. K. and Sokolov, V. Y. (1999), Correlation of Seismic Intensity with Fourier Acceleration Spectra, Phys. Chem. Earth 24, 523-528.

Chin, B.-H. and AKi, K. (1991), Simultaneous Study of the Source, Path, and Site Effects on Strong Ground Motion during the 1989 Loma Prieta Earthquake: A Preliminary Result on Pervasive Nonlinear Site Effects, Bull. Seismol. Soc. Am. 81, 1859-1884.

ChIn, B.-H. and AKI, K. (1996), Reply to Leif Wennerberg's Comment on "Simultaneous Study of the Source, Path, and Site Effects on Strong Ground Motion during the 1989 Loma Prieta earthquake: A Preliminary Result on Pervasive Nonlinear Site Effects", Bull. Seismol. Soc. Am. 86, 268-273.

Cocco, M. and Boatwright, J. (1993), The Envelopes of Acceleration Time Histories, Bull. Seismol. Soc. Am. 83, 1095-1114.

Cormier, V. F. (1982), The Effect of Attenuation on Seismic Body Waves, Bull. Seismol. Soc. Am. 72 , S169-S200.

Correig, A. M. (1996), On the Measurement of the Predominant and Resonant Frequencies, Bull. Seismol. Soc. Am. 86, 416-427.

De Natale, G., Faccioli, E., and Zollo, A. (1988), Scaling of Peak Ground Motions from Digital Recordings of Small Earthquakes at Campi Flegrei, Southern Italy, Pure Appl. Geophys. 126, 37-53.

EPRI (1993), Guidelines for Determining Design Basis Ground Motions, Electric Power Research Institute, Palo Alto, Calif., Rept. No. EPRI TR-102293, vols. 1-5.

Erdik, M. and Durukal, E. (2001), A Hybrid Procedure for the Assessment of Design Basis Earthquake Ground Motions for Near-fault Conditions, Soil Dyn. Earthq. Eng. 21, 431-443.

Faccioli, E. (1986), A Study of Strong Motions from Italy and Yugoslavia in terms of Gross Source Properties. In Earthquake Source Mechanics (S. Das, J. Boatwright, and C. Scholz, eds.), Amer. Geophys. Union Geophysical Monograph 37, 297-309.

Frankel, A., Mueller, C., Barnhard, T., Perkins, D., Leyendecker, E., Dickman, N., Hanson, S. and Hopper, M. (1996), National Seismic Hazard Maps: Documentation June 1996. U.S. Geol. Surv. Open-File Rept. 96-532, 69 pp.

Grosh, A. K. (1992), A Semianalytical Model for Fourier Amplitude Spectrum of Earthquake Ground Motion, Nuclear Engin. and Design 133, 199-208.

Greig, G. L. and Atkinson, G. M. (1993), The damage potential of eastern North American earthquakes, Seism. Res. Lett. 64, 119-137.

Gusev, A. A., Gordeev, E. I., Guseva, E. M., Petukhin, A. G., and Chebrov, V. N. (1997), The First Version of the $A(\max )(M(W), R)$ Relationship for Kamchatka, Pure Appl. Geophys. 149, 299-312.

Haddon, R. (1996), Earthquake Source Spectra in Eastern North America, Bull. Seismol. Soc. Am. 86, $1300-1313$.

Hanks, T. C. (1979), b Values and $\omega^{-\gamma}$ Seismic Source Models: Implications for Tectonic Stress Variations along Active Crustal Fault Zones and the Estimation of High-frequency Strong Ground Motion, J. Geophys. Res. 84, 2235-2242.

Hanks, T. C. (1982), $f_{\max }$, Bull. Seismol. Soc. Am. 72, 1867-1879.

Hanks, T. C. and Boore, D. M. (1984), Moment-Magnitude Relations in Theory and Practice, J. Geophys. Res. 89, 6229-6235.

Hanks, T. C. and Johnston, A. C. (1992), Common Features of the Excitation and Propagation of Strong Ground Motion for North American Earthquakes, Bull. Seismol. Soc. Am. 82, 1-23.

Hanks, T. C. and Kanamori, H. (1979), A Moment Magnitude Scale, J. Geophys. Res. 84, 23482350 . 
Hanks, T. C. and McGuire, R. K. (1981), The Character of High-frequency Strong Ground Motion, Bull. Seismol. Soc. Am. 71, 2071-2095.

Harik, I. E., Allen, D. L., Street, R. L., Guo, M., Graves, R. C., Harison, R. C., and Gawry, M. J. (1997), Seismic Evaluation of Brent-Spence Bridge, J. Struct. Eng. 123, 1269-1275.

HARMSEN, S. (2002), SEISMOGRAPHS FROM THE INTERACTIVE DEAGGREGATION WEB PAGE, HTTP://EQINT1.CR.USGS.GOV/EQ/HTML/STOCHASTIC_SEISMOGRAM_THEORY.HTML.

Hartzell, S. H. and Heaton, T. H. (1988), Failure of Self-similarity for Large $\left(M_{w}>81 / 4\right)$ Earthquakes, Bull. Seismol. Soc. Am. 78, 478-488.

Hartzell, S., Harmsen, S., Frankel, A., and Larsen, S. (1999), Calculation of Broadband Time Histories of Ground Motion: Comparison of Methods and Validation Using Strong-ground Motion from the 1994 Northridge Earthquake, Bull. Seismol. Soc. Am. 89, 1484-1504.

Hartzell, S., Leeds, A., Frankel, A., Williams, R. A., Odum, J., Stephenson, W., and Silva, W. (2002), Simulation of broadband ground motion including nonlinear soil effects for a magnitude 6.5 earthquake on the Seattle fault, Seattle, Washington, Bull. Seism. Soc. Am. 92, 831-853.

Herrero, A. and Bernard, P. (1994), A Kinematic Self-similar Rupture Process for Earthquakes, J. Geophys. Res. 84, 1216-1228.

Herrmann, R. B. (1985), An Extension of Random Vibration Theory Estimates of Strong Ground Motion to Large Distances, Bull. Seismol. Soc. Am. 75, 1447-1453.

Herrmann, R. B. and Akinci, A. (2000), Mid-America Ground Motion Models, http://www.eas.slu.edu/ People/RBHerrmann/MAEC/maecgnd.html.

Hisada, Y. (2000), A Theoretical Omega-square Model Considering the Spatial Variation in Slip and Rupture Velocity, Bull. Seismol. Soc. Am. 90, 387-400.

Hlatywayo, D. J. (1997), Seismic Hazard in Central Southern Africa, Geophys. J. Int. 130, 737-745.

Hwang, H. (2001), Simulation of Earthquake ground motion. In Monte Carlo Simulation (Schuelle \& Spanos, eds.) (Balkema, Rotterdam 2001) pp. 467-473.

Hwang, H. and Huo, J.-R. (1994), Generation of Hazard-consistent Ground Motion, Soil Dyn. Earthq. Eng. 13, 377-386.

Hwang, H. and Huo, J.-R. (1997), Attenuation Relations of Ground Motion for Rock and Soil Sites in Eastern United States, Soil Dyn. Earthq. Eng. 13, 363-372.

Hwang, H., Lin, H., and Huo, J.-R. (1997), Site Coefficients for Design of Buildings in Eastern United States, Soil Dyn. Earthq. Eng. 16, 29-40.

Hwang, H., Pezeshr, S., Lin, Y. W., He, J., and Chiu, J. M. (2001a), Generation of Synthetic Ground Motion, CD Release 01-02, Mid-America Earthquake Center, University of Illinois at UrbanaChampaign, Urbana, IL.

Hwang, H., LiU, J. B., and CHIU, Y. H. (2001b), Seismic Fragility Analysis of Highway Bridges, CD Release 01-06, Mid-America Earthquake Center, University of Illinois at Urbana-Champaign, Urbana, IL.

Iglesias, A., Singh, S. K., PACheco, J. F., and Ordaz, M. (2002), A source and wave propagation study of the Copalillo, Mexico, earthquake of 21 July 2000 ( $\left.M_{w} 5.9\right)$ : Implications for seismic hazard in Mexico City from inslab earthquakes, Bull. Seism. Soc. Am. 92, 1060-1071.

JibSON, R. W. (1993), Predicting Earthquake-induced Landslide Displacements Using Newmark's Sliding Block Analysis, Transportation Research Record 1411, National Research Council, Washington, D.C., 9-17.

Jibson, R. W., Harp, E. L., and Michael, J. A. (1998), A Method for Producing Digital Probabilistic Seismic Landslide Hazard Maps: An Example from the Los Angeles, California, Area, U.S. Geol. Surv. Open-File Rept. 98-113, 17 pp.

Joyner, W. B. (1984), A Scaling Law for the Spectra of Large Earthquakes, Bull. Seismol. Soc. Am. 74, 1167-1188.

Joyner, W. B. (1995), Stochastic Simulation of Near-source Earthquake Ground Motion. In Proceedings: Modeling Earthquake Ground Motion at Close Distances, Electric Power Research Institute report EPRI TR-104975, 8-1-8-24.

JoYner, W. B. (1997), Ground Motion Estimates for the Northeastern U.S. or Southeastern Canada. In Recommendations for Probabilistic Seismic Hazard Analysis: Guidance on Uncertainty and Use of Experts, Senior Seismic Hazard Analysis Committee (R. Budnitz, G. Apostolakis, D. Boore, L. Cluff, K. Coppersmith, A. Cornell, and P. Morris eds.), U.S. Nuclear Reg. Comm. Rept. NUREG/CR-6372, Washington, D.C. 
Joyner, W. B. (2000), Strong Motion from Surface Waves in Deep Sedimentary Basins, Bull. Seismol. Soc. Am. 90, S95-S112.

Joyner, W. B. and Boore, D. M. (1988), Measurement, Characterization, and Prediction of Strong Ground Motion, In Earthquake Engineering and Soil Dynamics II, Proc. Am. Soc. Civil Eng. Geotech. Eng. Div. Specialty Conf., June 27-30, 1988, Park City, Utah, 43-102.

Kamae, K. and Irikura, K. (1992), Prediction of site-specific strong ground motion using semiempirical methods, in Proc. of the Tenth World Conference on Earthquake Engineering, Madrid, Spain, 19-24 July 1992, 801-806.

Kamae, K., Irikura, K., and Pitarka, A. A. (1998), A Technique for Simulating Strong Ground Motion Using Hybrid Green's Function, Bull. Seismol. Soc. Am. 88, 357-367.

Koyama, J. The Complex Faulting Process of Earthquakes (Kluwer Academic Publishers, Dordrecht, The Netherlands (1997)), 194 pp.

Kumar, S. (2000), Evaluation and Reduction of Liquefaction Potential at a Site in St. Louis, Missouri, Earthquake Spectra 16, 455-472.

Lam, N., Wilson, J., and Hutchinson, G. (2000), Generation of Synthetic Earthquake Accelerograms Using Seismological Modeling: A Review, J. Earthq. Eng. 4, 321-354.

LiaO, Z.-P. and JIN, X. (1995), A Stochastic Model of the Fourier Phase of Strong Ground Motion, Acta Seismologica Sinica 8, 435-446.

Liu, L. and Pezeshr, S. (1998), A stochastic approach in estimating the pseudo-relative spectral velocity, Earthquake Spectra $14,301-317$.

Liu, L. and Pezeshr, S. (1999), An Improvement on the Estimation of Pseudoresponse Spectral Velocity Using RVT Method, Bull. Seismol. Soc. Am. 89, 1384-1389.

LoH, C.-H. (1985), Analysis of the Spatial Variation of Seismic Waves and Ground Movements from SMART-1 Array Data, Earthq. Eng. Struct. Dyn. 13, 561-581.

LoH, C.-H. and YeH, Y.-T. (1988), Spatial Variation and Stochastic Modeling of Seismic Differential Ground Movement, Earthq. Eng. Struct. Dyn. 16, 583-596.

Lomnitz-Adler, J. and Lund, F. (1992), The Generation of Quasi-dynamical Accelerograms from Large and Complex Seismic Fractures, Bull. Seismol. Soc. Am. 82, 61-80.

Luco, J. E. (1985), On Strong Ground Motion Estimates Based on Models of the Radiated Spectrum, Bull. Seismol. Soc. Am. 75, 641-649.

MaHDYIAR, M. (2002), Are NEHRP and Earthquake-based Site Effects in Greater Los Angeles Compatible?, Seism. Res. Lett. 73, 39-45.

Malagnini, L. and Herrmann, R. B. (2000), Ground-motion scaling in the region of the 1997 UmbriaMarche earthquake (Italy), Bull. Seism. Soc. Am. 90, 1041-1051.

Malagnini, L., Herrmann, R. B. and Di Bona, M. (2000), Ground-motion scaling in the Appennines (Italy), Bull. Seism. Soc. Am. 90, 1062-1081.

Margaris, B. N. and Boore, D. M. (1998), Determination of $\Delta \sigma$ and $\kappa_{0}$ from Response Spectra of Large Earthquakes in Greece, Bull. Seismol. Soc. Am. 88, 170-182.

Margaris, B. N. and Hatzidimitriou, P. M. (2002), Source spectral scaling and stress release estimates using strong-motion records in Greece, Bull. Seism. Soc. Am. 92, 1040-1059.

Margaris, B. N. and Papazachos, C. B. (1999), Moment-magnitude Relations Based on Strong-motion Records in Greece, Bull. Seismol. Soc. Am. 89, 442-455.

McGuire, R. K. Ground Motion Estimation in Regions with Few Data, Proc. 8th World Conf. Earthquake Engineering (Prentice-Hall, Inc., Englewood Cliffs, New Jersey, (1984)) II, pp. 327-334.

McGuire, R. K. and Hanks, T. C. (1980), RMS Accelerations and Spectral Amplitudes of Strong Ground Motion during the San Fernando, California, Earthquake, Bull. Seismol. Soc. Am. 70, 1907-1919.

McGuire, R. K., Becker, A. M., and Donovan, N. C. (1984), Spectral Estimates of Seismic Shear Waves, Bull. Seismol. Soc. Am. 74, 1427-1440.

Midorikawa, S. and Kobayashi, H. (1978), On Estimation of Strong Earthquake Motions with Regard to Fault, Proceedings 2nd Intern. Conf. Microzonation 2, 825-836.

Miles, S. B. and Ho, C. L. (1999), Rigorous Landslide Hazard Zonation Using Newmark's Method and Stochastic Ground Motion Simulation, Soil Dyn. and Earthq. Eng. 18, 305-323. 
Miyake, H., Iwata, T., and Irikura, K. (2001), Estimation of Rupture Propagation Direction and Strong Motion Generation area from Azimuth and Distance dependence of Source Amplitude Spectra, Geophys. Res. Lett. 28, 2727-2730.

Ólafsson, S. and Sigbjörnsson, R. (1999), A Theoretical Attenuation Model for Earthquake-induced Ground Motion, J. Earthq. Eng. 3, 287-315.

Ólafsson, S., Sigbjörnsson, R., and EinARsson, P. (1998), Estimation of Source Parameters and Q from Acceleration Recorded in the Vatnafjoll Earthquake in South Iceland, Bull. Seismol. Soc. Am. 88, 556-563.

Ou, G.-B. and Herrmann, R. B. (1990a), A Statistical Model for Ground Motion Produced by Earthquakes at Local and Regional Distances, Bull. Seismol. Soc. Am. 80, 1397-1417.

Ou, G.-B. and Herrmann, R. B. (1990b), Estimation Theory for Strong Ground Motion, Seism. Res. Lett. 61, 99-107.

Papageorgiou, A. S. and Aki, K. (1983a), A Specific Barrier Model for the Quantitative Description of Inhomogeneous Faulting and the Prediction of Strong Ground Motion. I. Description of the Model, Bull. Seismol. Soc. Am. 73, 693-722.

Papageorgiou, A. S. and Aki, K. (1983b), A Specific Barrier Model for the Quantitative Description of Inhomogeneous Faulting and the Prediction of Strong Ground Motion. Part II. Applications of the Model, Bull. Seismol. Soc. Am. 73, 953-978.

Pezeshr, S., Camp, C. V., Liu, L., and Greve, W. M. (2001), Site Specific Analysis Program (SSAP), version 1.06, Dept. of Civil Eng., U. of Memphis, Memphis, TN.

Pitarka, A., Somerville, P., Fukushima, Y., Uetake, T., and Irikura, K. (2000), Simulation of nearfault strong-ground motion using hybrid Green's functions, Bull. Seism. Soc. Am. 90, 566-586.

Pitarka, A., Somerville, P. G., Fukushima, Y., and Uetake, T. (2002), Ground-motion attenuation from the 1995 Kobe earthquake based on simlations using the hybrid Green's function method, Bull. Seism. Soc. Am. 92, 1025-1031

Raoof, M., Herrmann, R. B., and Malagnini, L. (1999), Attenuation and Excitation of Three-component Ground Motion in Southern California, Bull. Seismol. Soc. Am. 89, 888-902.

Rathje, E. M., Abrahamson, N. A., and Bray, J. D. (1998), Simplified Frequency Content Estimates of Earthquake Ground Motions, J. Geotech. Geoenviron. Eng. 124, 150-159.

Rice, S. O. Mathematical Analysis of Random Noise, reprinted in Selected Papers on Noise and Stochastic Processes (N. Wax, ed.) (Dover Publications, New York, 1954), pp. 133-294.

Roumelioti, Z. and Kiratzi, A. (2002), Stochastic simulation of strong-motion records from the 15 April 1979 (M7.1) Montenegro earthquake, Bull. Seism. Soc. Am. 92, 1095-1101.

Rovelli, A., Bonamassa, O., Cocco, M., Di Bona, M., and Mazza, S. (1988), Scaling Laws and Spectral Parameters of the Ground Motion in Active Extensional Areas in Italy, Bull. Seismol. Soc. Am. 78, 530560.

Rovelli, A., Cocco, M., Console, R., Alessandrini, B., and Mazza, S. (1991), Ground Motion Waveforms and Source Spectral Scaling from Close-distance Accelerograms in a Compressional Regime Area (Friuli, Northeastern Italy), Bull. Seismol. Soc. Am. 81, 57-80.

Rovelli, A., Caserta, A., Malignini, L., and Marra, F. (1994a), Assessment of Potential Strong Motions in the City of Rome, Annali di Geofisica 37, 1745-1769.

Rovelli, A., Malagnini, L., Caserta, A., and Marra, F. (1994b), Using 1-D and 2-D Modeling of Ground Motions for Seismic Zonation Criteria: Results for the City of Rome. Annali di Geofisica 38, 591605.

Sabetta, F. and Pugliese, A. (1996), Estimation of Response Spectra and Simulation of Nonstationary Earthquake Ground Motions, Bull. Seismol. Soc. Am. 86, 337-352.

ŞAFAK, E. and BoOre, D. M. (1988), On Low-frequency Errors of Uniformly Modulated Filtered Whitenoise Models for Ground Motions, Earthq. Eng. Struct. Dyn. 16, 381-388.

Saragoni, G. R. and Hart, G. C. (1974), Simulation of Artificial Earthquakes, Earthq. Eng. Struct. Dyn. 2, 249-267.

SATOH, T. (2002), Empirical frequency-dependent radiation pattern of the 1998 Miyagiken-nanbu earthquake in Japan, Bull. Seism. Soc. Am. 92, 1032-1039.

Satoh, T., Kawase, H., and Sato, T. (1997), Statistical Spectral Model of Earthquakes in the Eastern Tohoku District, Japan, Based on the Surface and Borehole Records Observed in Sendai, Bull. Seismol. Soc. Am. 87, 446-462. 
Savy, J. B., Foxall, W., and Abrahamson, N. (1998), Guidance for Performing Probabilistic Seismic Hazard Analysis for a Nuclear Plant Site: Example Application to the Southeastern Unted States, NUREG/CR 6607, UCRL-ID-133494.

Scherbaum, F. (1994), Modeling the Roermond Earthquake of 1992 April 13 by Stochastic Simulation of its High-frequency Strong Ground Motion, Geophys. J. Int. 119, 31-43.

Scherbaum, F., Palme, C. and Langer, H. (1994), Model parameter optimization for site-dependent simulation of ground motion by simulated annealing - reevaluation of the Ashigara valley prediction experiment, Natural Hazards 10, 275-296.

Schneider, J. and Silva, W. J. (2000), Earthquake Scenario Ground Motion Hazard Maps for the San Francisco Bay Region, Final report, USGS Grant award \#98-HQ-GR-1004.

Schneider, J. F., Silva, W. J., Chiou, S.-J., and Stepp, J. C. (1991), Estimation of Ground Motion at Close Distances Using the Band-limited-white-noise Model, Proc. Fourth International Microzonation Conf. II, $187-194$.

Schneider, J. F., Silva, W. J., and Stark, C. L. (1993), Ground Motion Model for the 1989 M 6.9 Loma Prieta Earthquake Including Effects of Source, Path and Site, Earthquake Spectra 9, 251-287.

Shapira, A. and VAn Eck, T. (1993), Synthetic Uniform-Hazard Site Specific Response Spectrum, Natural Hazards 8, 201-215.

Silva, W. J. (1992), Factors Controlling Strong Ground Motions and their Associated Uncertainties, Proc. Dynamic Analysis and Design Considerations for High Level Nuclear Waste Repositories, Structures Div./ Am. Soc. Civil Eng., 132-161.

Silva, W. J. (1997), Characteristics of Vertical Strong Ground Motions for Applications to Engineering Design, Proc. Of the FHWA/NCEER Workshop on the National Representation of Seismic Ground Motion for New and Existing Highway Facilities (I.M. Friedland, M.S. Power, and R.L. Mayes, eds.), Technical Report NCEER-97-0010.

Silva, W. J. and Costantino, C. (1999), Assessment of Liquefaction Potential for the 1995 Kobe, Japan Earthquake Including Finite-source Effects, Final Report, U.S Army Engineer Waterways Experiment Station, Corps of Engineers Contract \#DACW39-97-K-0015.

Silva, W. J. and Darragh, R. B. (1995), Engineering Characterization of Strong Ground Motion Recorded at Rock Sites, Electric Power Research Institute, Palo Alto, Calif., Report No. TR-102262.

Silva, W. J. and Green, R. K. (1989), Magnitude and Distance Scaling of Response Spectral Shapes for Rock Sites with Applications to North American Tectonic Environment, Earthquake Spectra 5, 591-624.

SILVA, W. J. and LEE, K. (1987), WES RASCAL code for Synthesizing Earthquake Ground Motions, Stateof-the-Art for Assessing Earthquake Hazards in the United States, Report 24, U.S. Army Engineers Waterways Experiment Station, Misc. Paper S-73-1.

Silva, W. J. and Wong, I. G. (1992), Assessment of Strong Near-field Earthquake Ground Shaking Adjacent to the Hayward fault, California. In Proc. Second Conf. on Earthq. Hazards in Eastern San Francisco Bay Area (Glenn Borchardt and others, eds.), Calif. Dept. of Conservation, Div. of Mines and Geology Special Publication 113, 503-510.

Silva, W. J., Turcotte, T., and Moriwaki, Y. (1988), Soil Response to Earthquake Ground Motion, Electric Power Research Institute, Palo Alto, California, Report No. NP-5747.

Silva, W. J., Darragh, R. B., Green, R. K., and Turcotte, F. T. (1989), Estimated Ground Motions for a New Madrid Event, U.S. Army Engineers Waterways Experiment Station, Misc. Paper GL-89-17.

Silva, W. J., Darragh, R., Stark, C., Wong, I., Stepp, J. C., Schneider, J., and Chiou, S.-J. (1990), $A$ Methodology to Estimate Design Response Spectra in the Near-source Region of Large Earthquakes Using the Band-limited-white-noise Ground Motion Model, Proc. Fourth U.S. Conf. on Earthq. Eng. 1, 487494.

Silva, W. J., Wong, I. G., and DARragh, R. B. (1991), Engineering Characterization of Earthquake Strong Ground Motions with Applications to the Pacific northwest, U.S. Geol. Surv. Open-File Rept. 91-441-H.

Silva, W. J., Abrahamson, N., Toro, G., and Costantino, C. (1997), Description and Validation of the Stochastic Ground Motion Model, Final Report, Brookhaven National Laboratory, Associated Universities, Inc. Upton, New York.

Silva, W. J., McGuire, R., and Costantino, C. (1999), Comparison of Site Specific Soil UHS to Soil Motions Computed with Rock UHS, Proc. of the OECE-NEA Workshop on Engineering Characterization of Seismic Input, Nov. 15-17, 1999, NEA/CSNI/R(2000)2. 
Silva, W. J., Darragh, R., Gregor, N., Martin, G., Kircher, C., and Abrahamson, N. (2000a), Reassessment of Site Coefficients and Near-fault Factors for Building Code Provisions, Final Report, USGS Grant award \#98-HQ-GR-1010.

Silva, W. J., Youngs, R. R., and IDriss, I. M. (2000b), Development of Design Response Spectral Shapes for Central and Eastern U.S. (CEUS) and Western U.S. (WUS) Rock Site Conditions. Proc. of the OECE-NEA Workshop on Engineering Characterization of Seismic Input Nov. 15-17, 1999 NEA/ CSNI/R(2000)2.

Silva, W., Gregor, N., and Darragh, R. (2002), Department of Regional Hard Rock Attenuation Relations for Central and Eastern North America, ftp:// ftp.pacificengineering.org/CEUS/

Singh, S. K., Ordaz, M., Anderson, J. G., Rodriguez, M., QuaAs, R., Mena, E., Ottaviani, M., and Almora, D. (1989), Analysis of Near-source Strong-motion Recordings along the Mexican Subduction Zone, Bull. Seismol. Soc. Am. 79, 1697-1717.

Singh, S. K., Ordaz, M., Dattatrayam, R. S., and Gupta, H. K. (1999), A Spectral Analysis of the 21 May 1997, Jabalpur, India, Earthquake $\left(M_{w}=5.8\right)$ and Estimation of Ground Motion from Future Earthquakes in the Indian shield region, Bull. Seismol. Soc. Am. 89, 1620-1630.

Singh, S. K., Mohanty, W. K., Bansal, B. K., and Roonwal, G. S. (2002), Ground motion in Delhi from future large/great earthquakes in the central seismic gap of the Himalayan arc, Bull. Seism. Soc. Am. 92, $555-569$.

Sokolov, V. (1997), Empirical Models for Estimating Fourier-amplitude Spectra of Ground Acceleration in the Northern Caucasus (Racha Seismogenic Zone), Bull. Seismol. Soc. Am. 87, 1401-1412.

Sokolov, V. Y. (1998), Spectral Parameters of the Ground Motions in Caucasian Seismogenic Zones, Bull. seismol. Soc. Am. 88, 1438-1444.

Sokolov, V. (2000a), Spectral Parameters of Ground Motion in Different Regions: Comparison of Empirical Models, Soil Dyn. Earthq. Eng. 19, 173-181.

Sokolov, V. Y. (2000b), Hazard-consistent ground motions: Generation on the basis of the uniform hazard Fourier spectra, Bull. Seism. Soc. Am. 90, 1010-1027.

Sokolov, V., Loh, C. H., and Wen, K. L (2000), Empirical Model for Estimating Fourier Amplitude Spectra of Ground Acceleration in Taiwan region, Earthq. Eng. Struct. Dyn. 29, 339-357.

Sokolov, V., Loh, C. H. and Wen, K. L. (2001), Empirical models for site- and region-dependent groundmotion parameters in the Taipei area: A unified approach, Earthquake Spectra 17, 313-331.

Suzuki, S., Hada, K., and Asano, K. (1998), Simulation of Strong Ground Motions Based on Recorded Accelerograms and the Stochastic Method, Soil Dyn. Earthq. Eng. 17, 551-556.

Tamura, K. and Aizawa, K. (1992), Differential Ground Motion Estimation Using a Time-space Stochastic Process Model, Proc. Japan Soc. Civil Eng. 8, 217-223.

Tamura, K., Winterstein, S. R., and Shah, H. C. (1991), Spatially Varying Ground Motion Models and their Application to the Estimation of Differential Ground Motion, Proc. Japan Soc. Civil Eng. 8, 153-161.

Toro, G. R. (1985), Stochastic Model Estimates of Strong Ground Motion, Section 3 of Seismic Hazard Methodology for Nuclear Facilities in the Eastern United States, Report Prepared for EPRI, Project Number P101-29.

Toro, G. R., and McGuire, R. K. (1987), An Investigation into Earthquake Ground Motion Characteristics in Eastern North America, Bull. Seismol. Soc. Am. 77, 468-489.

Toro, G. R., McGuire, R. K., and Silva, W. J. (1988), Engineering Model of Earthquake Ground Motion for Eastern North America, Electric Power Research Institute, Palo Alto, Calif., Rept. No. RP-6074.

Toro, G. R., Silva, W. J., McGuire, R. K., and Herrmann, R. B.(1992), Probabilistic Seismic Hazard Mapping of the Mississippi Embayment, Seism. Res. Lett. 63, 449-475.

Toro, G. R., Abrahamson, N. A., and Schneider, J. F. (1997), Model of Strong Ground Motions from Earthquakes in Central and Eastern North America: Best Estimates and Uncertainties, Seism. Res. Lett. 68, 41-57.

Tremblay, R. and Atkinson, G. M. (2001), Comparative study of the inelastic seismic demand of eastern and western Canadian sites, Earthquake Spectra 17, 333-358.

Tsai, C. C. P. (1997), Ground Motion Modeling for Seismic Hazard Analysis in the Near-source Regime: An Asperity Model, Pure Appl. Geophys. 149, 265-297.

Tsai, C. C. P. (1998a), Ground Motion Modeling in the Near-source Regime: A Barrier Model, Terrestrial Atmosph. Oceanic Sci. 9, 15-30. 
TsaI, C. C. P. (1998b), Engineering Ground Motion Modeling in the Near-source Regime Using the Specific Barrier Model for Probabilistic Seismic Hazard Analysis, Pure Appl. Geophy. 152, 107-123.

Tumarkin, A. G. and Archuleta, R. J. (1994), Empirical Ground Motion Prediction, Annali di Geofisica 37, 1691-1720.

Vetter, U. R., Ake, J. P., and Laforge, R. C. (1996), Seismic Hazard Evaluation for Dams in Northern Colorado, USA, Natural Hazards 14, 227-240.

Wen, Y. K. and Wu, C. L. (2001), Generation of Ground Motions for Mid-America Cities, Earthquake Spectra $17,359-384$.

Wennerberg, L. (1990), Stochastic Summation of Empirical Greens Functions, Bull. Seismol. Soc. Am. 80, 1418-1432.

Wennerberg, L. (1996), Comment on "Simultaneous Study of the Source, Path, and Site Effects on Strong Ground Motion During the 1989 Loma Prieta Earthquake: A Preliminary Result on Pervasive Nonlinear Site Effects" by Byau-Heng Chin and Keiiti Aki, Bull. Seismol. Soc. Am. 86, 259-267.

Wilson, R. C. (1993), Relation of Arias Intensity to Magnitude and Distance in California, U. S. Geol. Surv. Open-File Rept, 93-556 42 pp.

Wong, I. G. and Silva, W. J. (1990), Preliminary Assessment of Potential Strong Earthquake Ground Shaking in the Portland, Oregon, Metropolitan Area, Oregon Geology 52, 131-134.

Wong, I. G. and Silva, W. J. (1993), Site-specific Strong Ground Motion Estimates for the Salt Lake Valley, Utah, Utah Geological Survey Misc. Publ. 93-9.

Wong, I. G. and Silva, W. J. (1994), Near-field Strong Ground Motions on Soil Sites: Augmenting the Empirical Data Base through Stochastic Modeling, Proc. Fifth U.S. National Conference on Earthquake Engineering, Chicago, July 10-14, 1994, III, 55-65.

Wong, I. G., Silva, W. J., Darragh, R. B., Stark, C., and Wright, D. H. (1991), Applications of the Band-limited-white-noise Source Model for Predicting Site-specific Strong Ground Motions, Proc. Second Int. Conf. on Recent Advances in Geotech. Earthq. Eng. and Soil Dynamics, Paper 9.13, 1323-1331.

Wong, I. G., Silva, W. J., and Madin, I. P. (1993), Strong Ground Shaking in the Portland, Oregon, Metropolitan Area: Evaluating the Effects of Local crustal and Cascadia Subduction Zone Earthquakes and Near-surface Geology, Oregon Geology 55, 137-143.

Youngs, R. R. and Silva, W. J. (1992), Fitting the $\omega^{-2}$ Brune Source Model to California Empirical Strong Motion Data (abs.), Seism. Res. Lett. 63, 34.

Yu, G., Anderson, J. G. and Siddharthan, R. (1993), On the Characteristics of Nonlinear Soil Response, Bull. Seismol. Soc. Am. 83, 218-244.

Zeng, Y. H., Anderson, J. G., and Yu, G. A. (1994), Composite Source Model for Computing Realistic Synthetic Strong Ground Motions, Geophys. Res. Lett. 21, 725-728.

(Received July 2, 2000, accepted February 21, 2001)

(10) To access this journal online: http://www.birkhauser.ch 